DIVISION OF THE HUMANITIES AND SOCIAL SCIENCES

CALIFORNIA INSTITUTE OF TECHNOLOGY

PASADENA, CALIFORNIA 91125

PRODUCTION, TRADE, PRICES, EXCHANGE RATES AND

EQUILIBRATION IN LARGE EXPERIMENTAL ECONOMIES

Charles Noussair

Emory University

Charles Plott

California Institute of Technology

Raymond Riezman

University of lowa

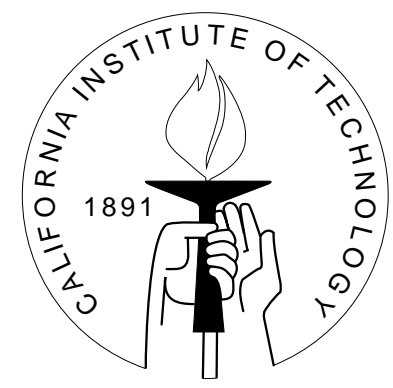

SOCIAL SCIENCE WORKING PAPER 1188

July 2005 


\title{
Production, Trade, Prices, Exchange Rates and Equilibration in Large Experimental Economies
}

\author{
Charles Noussair Charles Plott Raymond Riezman
}

\begin{abstract}
We study market equilibration in laboratory economies that are larger and more complex than any that have been studied experimentally to date. Complexity is derived from the fact that the economies are international in economic structure with multiple input, output, and foreign exchange markets in operation. The economies have twenty-one markets and due to the fact that they have roughly fifty agents, the economies are characterized by several hundred equations. In spite of the complexity and interdependence of the economy, the results demonstrate the substantial power of the general equilibrium model of perfect competition to predict the direction of movement of market-level variables. Empirical patterns in the convergence process are explored and described.
\end{abstract}




\title{
Production, Trade, Prices, Exchange Rates and Equilibration in Large Experimental Economies
}

\author{
Charles Noussair Charles Plott Raymond Riezman
}

1 let it go 


\title{
Production, Trade, Prices, Exchange Rates and Equilibration in Large Experimental Economies
}

\author{
Charles Noussair, Charles Plott and Raymond Riezman ${ }^{1}$
}

\section{Introduction}

Under the classical competitive equilibrium model, the simultaneous optimization by all participants in the economy, given prices, incentives, resources, and technology constraints, implies an outcome corresponding to a solution of a system of nonlinear excess demand equations. The number of such equations explodes as the number of commodities and resources increase, but the theory itself suggests no effects of the increased complexity. On the surface, the thought that a decentralized system of competitively interacting humans might approximate the solution as the number of equations grows large is a staggering and contentious proposition that many cannot believe without demonstration. The substance of this paper is a demonstration that equilibration is not beyond the capacity of a large economic system and that the principles at work are well approximated by classical general equilibrium theory applied to international economies.

Although the concept of equilibrium is static, part of its allure as a predictive model lies in a dynamic interpretation; that the movement of the economic variables will be in the direction of the equilibrium of the model. The empirical relevance of such a dynamic interpretation of the model is demonstrated in a growing body of experimental work that documents a convergence tendency in markets. That is, in many reported experiments, there is a tendency for markets to converge toward the competitive equilibria of corresponding theoretical models, and for the market activity to exhibit reduced variability in a neighborhood of the equilibrium prices and quantities. In such cases, Equilibration, a dynamic principle of system behavior, underlies the support for the law of supply and demand. This convergence generalizes to a wide class of experimental economies, such as production economies with derived demand (Goodfellow and Plott, 1990; Plott and George, 1983), exchange economies with two or more commodities (Forsythe et al. 1980; Plott and Sunder, 1988; Plott, 1988; Bossaerts et al. 2001; Plott, 2001; Williams et al., 2001; Chen and Plott, 2001), and small general equilibrium systems with a circular flow of income (Lian and Plott, 1998). ${ }^{2}$

In this paper we investigate the properties of the equilibration process of experimental international market economies. These economies are far more complex

\footnotetext{
${ }^{1}$ Noussair: Department of Economics, Rich Memorial Building, Emory University, Atlanta, GA 303222240, USA. E-mail cnoussa@emory.edu. Plott: Division of the Humanities and Social Sciences, California Institute of Technology, Pasadena, CA 91125, USA. E-mail: cplott@hss.caltech.edu. Riezman: Department of Economics, University of Iowa, Iowa City, IA 52242, USA. E-mail: raymond-riezman@uiowa.edu. We thank Carol McAusland, Jacob Goeree, Zheng Liu, and seminar participants at Nottingham University, the University of Amsterdam, and the Hong Kong University of Science and Technology for helpful comments. We thank Steven Tucker and Tara Larson for research assistance.

${ }^{2}$ While a dynamic process of price adjustment is in operation, it need not necessarily lead in the direction of the competitive equilibrium. The process can be unstable (Plott and George, 1990; Plott and Smith, 1999; Plott 2000) or cycle without apparent equilibration (Anderson et al., 2003).
} 
that any laboratory economies created to date. The complexity is not only in terms of the number of commodities, markets and agents, but also in terms of the nature of the economic activities and their interdependence. In international economies, special types of market interdependencies arise because international demand for traded goods also influences derived demand for factors of production. Moreover, exchange rates exert direct feedback on all sectors of the economy and the demand and supply of foreign exchange are sensitive to various activities throughout the economy. The feasibility of studying simpler international economies has been established (Noussair et al., 1995, $1997^{3}$; Riedl and van Winden, 2001), together with a presumption that the equilibration tendencies of systems of markets will survive in even the most complex of environments.

In the experiment reported here, the laboratory world is divided into three countries, where each country is characterized by its own currency, resource endowment, and production technology. There are three final goods, which can be produced in any of the three countries. Two input goods, both of which are required to produce any of the outputs, reside in each of the three countries. These factors of production are immobile, although outputs can be traded internationally. Markets exist for each output, input and currency. The simultaneous trade of several types of goods, factors of production, final goods, and currencies, provides a rich setting to study the principles of behavior of an entire general equilibrium economic system, with interdependencies beyond those that have been previously studied experimentally.

The paper is divided into five sections. The first section is this introduction. The second section describes the experimental environment together with the procedures and parameters. Because this is the first experiment with this level of complexity, section two also includes some details about the interfaces and other aspects of the experiment. The third section is a summary of the models and terminology that are used in the results section. The analysis is conducted at the aggregate level to identify and explore patterns of behavior of economic systems rather than those of individuals. The concept of equilibration is expressed in a testable formulation called the Equilibration Hypothesis. The hypothesis has two parts: (1) Reduced variability: the variance of the variables in the system decreases over time, and (2) Convergence: the values of the variables move in the direction of the Competitive Equilibrium values.

The fourth section describes the results from the experiment and the last section presents and discusses the conclusions. After evaluating the equilibration hypothesis, which is supported in our data, the empirical characteristics of the equilibration process are explored. The behavior of variables such as national production, international trade,

\footnotetext{
${ }^{3}$ Noussair et al. (1995) consider two types of experimental international economies. The first has the structure of the Ricardian model, in which there are two countries, two output goods, and one input good. In the competitive equilibrium, full specialization by each country in one output is predicted. The authors observe convergence to the equilibrium, though input prices are lower than marginal products and tariffs reduce efficiency by a greater amount than is consistent with equilibrium comparative statics. The second type of economy has two inputs rather than one. Convergence to close to competitive equilibrium is also observed, and in both types of economy, trade flows are consistent with the Law of Comparative Advantage. While the economies studied in Noussair et al. (1995) have one currency common to both countries, Noussair et al. (1997) study experimental international exchange economies with two countries and two currencies. They find that trade patterns are consistent with the Law of Comparative Advantage, but the exchange rate deviates considerably from the Purchasing Power Parity level.
} 
prices, wages, and exchange rates, are studied. Some properties of the equilibration process that appear in our data and that we believe are fairly general are identified.

\section{The Experiment}

\section{2a. Overview of the Economy}

The economies we constructed all had the structure shown in figure 1 . There were three countries, $A, B$, and $C$. In each country there were agents who were suppliers. Suppliers were endowed with the ability to supply two resources, $l$ and $k$, to input markets. In each country there were also agents who were producers. Each producer was endowed with a production capability and could produce one of three outputs $x, y$, and $z$ using the inputs $l$ and $k$. Finally, there were consumers who could purchase $x, y$, and $z$ from producers on the output markets.

The final goods $x, y$, and $z$ could trade freely internationally but the inputs $l$ and $k$ could not trade internationally. Each country had its own currency, labeled as $A, B$, or $C$, and all transactions within a country were required to take place in terms of domestic currency. We also imposed the requirement that only domestic currency had value to residents of a given country, and at the close of the market period all foreign currency was removed from the inventory of all agents. ${ }^{4}$

A cash-in-advance constraint was in effect on international transactions. Imports into country $J$ could occur only when a resident of country $J$ transported a good into country $J$. It was not possible for a resident of country $J$ to transport goods produced in $J$ to country $K$ for sale there. This meant that a prospective purchaser from country $K$, who wished to purchase a good produced in country $J$, had to obtain currency $J$ before international trade could take place. To obtain foreign currency, agents could use currency markets that were operating in all three countries. The cash in advance constraint ensured that the currency markets would be active if international trade occurred.

The cash-in-advance requirement not only conforms to what is typically actually the case in field economies, but is also helpful in terms of experimental design. Without this requirement it would be very difficult to precisely determine the equilibrium demand for foreign currency and hence, the calculation of predicted equilibrium would be problematic. We could have imposed the condition that producers sell to consumers in the consumer's home currency but we are confident that the qualitative results would be the same. The only difference would be which agents bear the foreign exchange risk. The important point to remember is that foreign exchange risk in experimental economies will exist no matter how the experiment is designed. This is because decisions are made sequentially and international transactions require introducing currency markets which creates an additional decision that agents must make. Thus, regardless of the experimental design, there must be agents who must buy and sell foreign currency before they know the transaction price and quantity of the commodities they are trading. This creates an unavoidable risk.

\footnotetext{
${ }^{4}$ This is done so that the only sources of demand for currency were the importation of goods or intra-period speculation in the currency market. It would be interesting to allow foreign exchange to be carried over to future periods but this would substantially complicate the experiment since all agents would have a speculative motivation to hold currencies over the entire length of the experiment.
} 
For the economy to maximize gains from trade, the following pattern of activity must occur. Suppliers sell inputs $l$ and $k$ to producers in their own country. Producers purchase domestic $l$ and $k$ and use them in the production of the outputs $x, y$, or $z$. Producers then sell the outputs to domestic and foreign consumers. Consumers purchase $x, y$, and $z$ from domestic and/or foreign producers. To purchase a good from a foreign producer the consumer first buys the currency of the country from which he wishes to import. Supply of the foreign currency originates from foreign consumers who also wish to import goods into their own country.

[Figure 1: About Here]

\section{2b. Parameters}

Subjects had several sources of incentives. Consumers' valuations for outputs $x, y$, and $z$ were induced by assigning them exogenous values in terms of domestic currency. If a consumer purchased and later consumed a unit at a price below its valuation to him, he would earn a profit on the unit. The marginal valuations for an individual consumer for the outputs decreased as he consumed more. Suppliers' costs to supply the inputs $l$ and $k$ were also induced. ${ }^{5}$ They were required to pay a marginal cost for each unit they wished to sell, and would make a profit on a unit if the price at which it sold was greater than its marginal cost.

Incentives for consumption activities are denoted as $U(x, y, z)$. Consumers had induced values for the three goods. The utilities were in terms of home currency, which would be converted into U.S. dollars at the end of the experiment. The induced preferences of a consumer $i$, in terms of U.S. dollars, had the form ${ }^{6}$ :

$$
U_{i}\left(x^{i}, y^{i}, z^{i}\right)=\alpha^{i}\left[\beta^{i} x^{i}+.5 \delta^{i}\left(x^{i}\right)^{2}+\gamma_{i} y^{i}+.5 \eta^{i}\left(y^{i}\right)^{2}+\kappa^{i} z^{i}+.5 v^{i}\left(z^{i}\right)^{2}\right]
$$

$\alpha^{i}$ is the conversion rate for subject $i$ from the currency of the country in which he resides to his final payment in US dollars. The utility function is separable in the three goods and quadratic in each of the goods. When presented to subjects, consumer incentives were expressed in terms of integer quantities of home currency and marginal utilities, $\left[1 / \alpha^{i}\right]$ $\left[U_{i}(q)-U_{i}(q-1)\right]$ where $q$ is one of the consumption goods.

Supplying resources is costly to the supplier and thus enters as a negative in a utility calculation. The cost of supplying resources is denoted as $C(l, k)$. The incentives of suppliers are derived from their ability to acquire resources at a cost in terms of home currency and sell them for home currency at a profit. The induced cost to a supplier $i$ of inputs is quadratic, separable in the two inputs and is approximated with the following functional form:

$$
C_{i}\left(l^{i}, k^{i}\right)=\varphi^{i} l^{i}+\theta^{i}\left(l^{i}\right)^{2}+\mu^{i} k^{i}+\tau^{i}\left(k^{i}\right)^{2} .
$$

\footnotetext{
${ }^{5}$ The variable names $V$ and $W$ were used in the experiment to refer to the inputs. To facilitate their interpretation as factors of production, for purposes of exposition we refer to $V$ as $l$ and $W$ as $k$.

${ }^{6}$ This is the general form of the utility function. In the actual utility functions we use in the experiment, some of these parameters are set to zero for some individuals.
} 
Each producer had the capacity to transform the two resources into one of the three outputs. This ability to transform goods represents a production capability. By purchasing the resources with home currency, producing the output, and selling it for home currency, the producer could make a profit in terms of home currency, which would later be converted to dollars. Therefore, producers had an incentive to maximize profits in terms of home currency. Let $f_{J}^{m}(k, l)$ denote the production function of a producer in country $J$ for output $m$. The production function of individual $i$ took the form $^{7}$ :

$$
f_{J}^{m i}(k, l)=H_{J}^{m}\left(l^{i}\right) \cdot 25\left(k^{i}\right)^{25}
$$

Each participant was assigned one of twelve possible types. The types indicated their country of residence, and the incentives and production technologies at their disposal. Most types had more than one role as consumer, producer or supplier, although no subject was both a producer and a supplier, and no subject was both a producer and a consumer of the same good. These restrictions ensured that all inputs used in production and all outputs consumed were traded between different individuals so that the price of every unit transacted of every good could be measured and recorded. Table 1 contains the continuous approximations of the functions of the goods defining each type of agent and the number of agents of each type that there were in each experiment. The actual discrete parameter functions given to each type are available from the authors.

\section{[Table 1: About Here]}

Earnings of each participant $i$ in each period were given by $M_{d}^{F i}-M_{d}^{B i} . M_{d}^{F i}$ is $i$ 's holding of domestic currency at the end of the period, while $M_{d}{ }^{B i}$ is the holding of domestic currency at the beginning of the period. $M_{d}^{F i}-M_{d}^{B i}$ is equal to $U_{i}\left(x^{i}, y^{i}, z^{i}\right)-$ $C_{i}\left(l^{i}, k^{i}\right)+R_{i}\left(x, y, z, l, k, M_{f}\right)-E_{i}\left(x, y, z, l, k, M_{f}\right) . U_{i}\left(x^{i}, y^{i}, z^{i}\right)$ and $C_{i}\left(l^{i}, k^{i}\right)$ are included in the final total holding of domestic currency, because the value of an individual's consumption was added to his cash balance and the cost of supplying inputs was deducted from his cash balance. $R_{i}\left(x, y, z, l, k, M_{f}\right)$ and $E_{i}\left(x, y, z, l, k, M_{f}\right)$ are individual $i$ 's revenues from sales to and the expenditures on purchases from other agents. All agents were free to purchase and resell in any market and therefore could speculate on price changes within a period. $M_{f}$ denotes foreign currency, which could be bought and sold with domestic currency.

\section{2c. The Interface}

In the experimental economies, 21 markets, in which all subjects could participate at all times, were in operation. There were seven markets located in each country. Each country contained a market for each of the three outputs $x, y$, and $z$, and for each of the two inputs $l$ and $k$. Each country also contained two currency markets. In each currency market, domestic currency could be exchanged for one of the two foreign currencies. All markets followed continuous double auction rules. The experiment was computerized and used the Marketscape platform developed at the California Institute of Technology. The computer program was written in PERL and runs on the LINUX operating system. Each

\footnotetext{
${ }^{7}$ Notice that these production functions exhibit decreasing returns to scale. Since the number of firms cannot change (entry is not allowed into any industry) in the experiment this causes no problems.
} 
subject accessed the markets using a web browser. The principal interface for the subjects was the Market Summary Screen, illustrated in figure 2.

[Figures 2 and 3: About Here]

There was one market screen corresponding to each country and links on the bottom of the screen that allowed the user to move between countries. Subjects could submit offers to buy or sell by filling out the rightmost portion of the screen. The subject specified whether the offer was to buy or sell, the good offered, the number of units, the price, and the time period for which the offer was to be available. The order book for each good was displayed on a screen that subjects reached if they selected the name of the market on their main screen. To accept an offer another participant submitted, an agent could select a box next to the offer she was accepting.

The demand functions of consumers for final goods and the supply functions of suppliers for inputs were stationary. Consumers could sell units of $x, y$, and $z$ to the experimenter, and receive cash in return. These sales were considered consumption and the cash received for the sale, which was added to the cash balance of the consumer, represented the utility of consumption. Similarly, suppliers could purchase units of $l$ and $k$ from the experimenter at predetermined prices for resale to producers. The price the supplier paid for each unit represented the marginal cost of supplying that unit and was deducted from the supplier's earnings.

The links at the bottom of the screen illustrated in figure 2 illustrate the information available at any time to participants. At any time, subjects could access the current offers available to every domestic and foreign market. In addition to being able to view all current offers in all markets, they could go to pages that would list their own history of offers and a history of transactions for each good for the current and all previous periods of the experiment. The latter information was available in both text and graphical form. They could also select Announcements and receive public messages from the experimenter. ${ }^{8}$

A producer's production function was displayed in the manner shown in figure 3. The numbers in the table correspond to the total output that could be produced with given quantities of the two inputs within a period. The numbers in the table form an isoquant map of the producer's production function. Production was restricted to integer amounts. Over the course of a period, as inputs were used in production, a highlighted cursor would track input use from the origin outward. This facilitated the calculation of the current marginal product at any point in time. To produce output subjects used another, interactive screen that allowed them to calculate hypothetically the quantity they could produce with different combinations of inputs before they committed themselves to the irreversible production decision. To produce, they typed input quantities in designated fields.

\section{2d. The Sessions}

\footnotetext{
${ }^{8}$ When the experimenter sent a message to subjects that could be read on the Announcements page, an alert appeared on the main screen indicating that there was a new message for the subjects from the experimenter.
} 
Three independent experiments were conducted. Experiment 1 took place during three three-hour sessions on three different days, and experiments 2 and 3 during two four-hour sessions on two different days. The same subject took part in all of the sessions that made up an individual experiment, but no subject took part in more than one experiment. In experiment 1 , there were 60 participants, 46 of whom were undergraduates at Purdue University and 14 of whom were undergraduates at the California Institute of Technology. In experiment 1 , all subjects were located in the economics laboratories at Purdue University and the California Institute of Technology during the sessions. In experiments 2 and 3, there were 40 and 57 subjects, respectively, who were all undergraduate students at Caltech. Sessions 2 and 3 were conducted remotely with all subjects connecting from outside the laboratory over the Internet using a web browser.

The experiments consisted of a sequence of periods. All markets were open for the entire duration of each period. In each period all values of the parameters were reinitialized to the same starting values so that the underlying parameters remained the same within each period of a given experiment. Thus, there was no ability to carry over inventories or to accumulate capital from period to period. Experiment 1 consisted of 12 periods and experiments 2 and 3 consisted of 16 periods. Each period was between 20 and 30 minutes in length. The time remaining in the current period was always common knowledge.

\section{2e. Competitive equilibrium}

Application of the model of perfect competition can be used to produce market demand functions for each commodity in each country. These are themselves complex, being derived from individual maximization theory, inverted and summed across agents. Thus, the summary equations in this subsection represent a major simplification of the economic environment that existed.

The demand functions of individual consumers for the three outputs in each of the three countries were discrete approximations of functions of the form $d_{m}{ }^{J}\left(p_{m}{ }^{J}\right)=a_{m}{ }^{J}-b_{m}{ }^{J}$

$* p_{m}{ }^{J}$, where $d_{m}{ }^{J}\left(p_{m}{ }^{J}\right)$ denotes the demand function of a consumer for good $m$ in country $J$ and $p_{m}{ }^{J}$ is the price of good $m$ in country $J$. The demand functions are calculated from the incentives described in equation (1). They are defined for non-negative quantities and prices and are denominated in domestic currency. The values of the demand parameters $\left(a_{m}{ }^{J}, b_{m}{ }^{J}\right)$ in effect in the experiment are given in table 2.

\section{[Table 2: About Here]}

The production technologies available to producers were approximations of (3). The values of the productivity parameters are given in table 2 . Country $A$ had a comparative (as well as an absolute) advantage in the production of $x, B$ in $y$, and $C$ in $z$. $f_{m}{ }^{J}(k, l)$ denotes the production function of a single producer of output $m$ in country $J$. The supply function of a supplier of factor $m$ in country $J$ is denoted as $s_{m}{ }^{J}\left(w_{m}{ }^{J}\right)=\mathrm{c}_{m}{ }^{J} * w_{m}{ }^{J}-$ $\mathrm{e}_{m}{ }^{J}$, and the parameter values are given in table 2 .

The competitive equilibrium of the economy can be found by solving a system of 23 equations. The first nine equations are market-clearing conditions in the output market of the form described in (4). $D_{m}^{J}\left(p_{m}^{J}\right)=\Sigma d_{m}^{J}\left(p_{m}^{J}\right)$ and $S_{m}^{J}\left(p_{m}^{J}\right)=\Sigma s_{m}^{J}\left(p_{m}^{J}\right)$ denote 
market demand and supply for good $m$ in country $J$ respectively. ${ }^{9} I M P_{m}^{J}$ is equal to the net imports of good $m$ into country $J$. The equations say that the amount of a commodity that is consumed in a country equals the net imports of the commodity into the country plus the home production of the commodity. ${ }^{10}$ That is, for $J=A, B$, and $C$, and $m=x, y$, and $z$ :

$$
D_{m}^{J}\left(p_{m}^{J}\right)=S_{m}^{J}\left(p_{m}^{J}\right)+I M P_{m}^{J}
$$

Six equations of the form (5) describe the market-clearing conditions for the two inputs in the three countries. They say that the wage of a factor is such that the quantity of the factor demanded in a country is equal to the amount that is supplied in that country. International trade in the inputs $k$ and $l$ is not permitted. For $m=\{l, k\}$ and $J=\{A, B, C\}$ :

$$
D_{m}^{J}\left(w_{m}^{J}\right)=S_{m}^{J}\left(w_{m}^{J}\right)
$$

Another six equations in the system are Law of One Price conditions, and are of the form (6). They require that prices of outputs in different countries be equal, adjusting with the appropriate exchange rate. $r^{B}$ is the exchange rate of currency $B$ for currency $A$ ( $r^{B}$ units of currency $B$ trade for one unit of currency $A$ ). $r^{C}$ is the exchange rate of currency $C$ for $A$. For $J=\{B, C\}$ and $m=\{x, y, z\}$ :

$$
p_{m}^{A}=r^{J} * p_{m}^{J}
$$

The final three equations reflect the flow of funds theory of exchange rates. They require that exchange rates adjust so that the demand for foreign exchange as dictated by imports equals the supply of foreign exchange as dictated by exports. Since the third equation is a linear combination of the first two, only (7) and (8) are used to compute the competitive equilibrium.

$$
\begin{aligned}
& p_{x}^{A} *\left(I M P^{B}{ }_{x}+I M P^{C}{ }_{x}\right)=p^{B}{ }_{y} * I M P^{A}{ }_{y} / r_{B}+p_{z}^{C} * I M P_{z}^{A} / r_{C} \\
& p_{y}^{B} *\left(I M P^{A}{ }_{y}+I M P_{y}^{C}\right)=p_{x}^{A} * I M P^{B}{ }_{x} * r_{B}+p_{z}^{C} * I M P_{z}^{B} * r_{B} / r_{C} \\
& p_{z}^{C} *\left(I M P_{z}^{A}+I M P_{z}^{B}\right)=p_{x}^{A} * I M P_{z}^{C} * r_{C}+p_{y}^{B} * I M P_{y}^{C} * r_{C} / r_{B}
\end{aligned}
$$

Market demands and supplies can be calculated in a straightforward manner from the individual demands and the data in tables 1 and 2. Table 3 contains the solution to the

\footnotetext{
${ }^{9}$ The supply of outputs and the demand for inputs are calculated from the production functions in a straightforward manner. An individual firm producing output $m$ and residing in country $J$ has a factor demand for input $k$ with the form: $\left.d_{k}^{J}(\boldsymbol{p}, \boldsymbol{w})=\left(H_{m}{ }^{J} p_{m}{ }^{J}\right)^{2} /\left(16\left(w_{k}{ }^{J}\right)^{1.5}\left(w_{l}{ }^{J}\right)^{.5}\right)\right)$, where $H_{m}{ }^{J}=4$ for $x$ in country $A$, $y$ in country $B$, and $z$ in country $C . H_{m}{ }^{J}=2$ for all other goods in the three countries. The market level demand for an input in each country is calculated by summing the demand of the factor over all firms. The market supply of a firm selling output $M$ in country $J$ is given by $s_{m}{ }^{J}(\boldsymbol{p}, \boldsymbol{w})=\left(H_{m}\right)^{{ }^{2}} p_{m}{ }_{m} /\left(\left(w_{k}{ }^{J}\right)^{.5}\left(w_{l}\right)^{J}\right)^{.5}$. A country's market supply for an output is calculated by summing the supply of individual firms.

${ }^{10}$ Countries $A, B$, and $C$ have comparative advantages in $x, y$, and $z$ respectively. In equilibrium they each export that good. Country $A$ imports $y$ and $z, B$ imports $x$ and $z$, and $C$ imports $x$ and $y$.
} 
23 equation system for each experiment. The solution defines a set of testable predictions, to which we shall refer as the Competitive Model, which are the competitive equilibrium values of the variables. These differ between the experiments because of the different numbers of agents of each of the twelve types. From the values in the table, the quantities of production and consumption of outputs, as well as the quantity of each input employed in the production of each output under the Competitive Model, can be calculated.

\section{[Table 3: About Here]}

\section{2f: An Alternative: The Autarky Model}

An alternative model to the competitive equilibrium, which we call the autarky model, assumes that there is no international trade and that the currency markets are inactive. Within each country, prices and wages clear the domestic markets. The predictions of the autarky model are calculated as the solution of nine equations of the form (4) and six of the form (5), with all of the international trade terms $I M P_{m}^{J}$ constrained to equal zero. In other words, the autarky model is the Walrasian equilibrium of each country $J$ 's economy under the assumption that it is completely isolated from other countries. The predictions of the autarky model for each of the three experiments are given in table 3 , along with those of the competitive model.

In these economies, the autarky model is not as unreasonable a predictive model as one might think at first glance. International trade includes some risks. An importer must first purchase foreign currency, which has no value to him at the end of the trading period, in order to make purchases in a foreign country. The currency market purchases must be of a sufficient quantity to allow the importer to complete the foreign purchases, yet not be of such a large quantity that unspent foreign currency cannot be resold for domestic currency before the end of the period. If an insufficient number of agents are willing to engage in international trade, the currency markets may become thin, eventually discouraging all traders from using them, and as a consequence causing the disappearance of international trade. Conceptually, in the light of complexity, risk aversion, and transactions costs, autarky might be the only stable equilibrium so it cannot be simply dismissed without examination.

\section{Statistical Methodology}

The Equilibration Hypothesis has two components, reduced variability and convergence. Reduced variability is a notion of decreasing variability of the value of a market-level variable over time, where a unit of time is defined as a market period. It can be defined for any input price, output price, exchange rate, or quantity produced, traded and consumed of any good at either the national or international level.

To evaluate whether or not reduced variability is occurring, we calculate the normalized standard deviation of prices, wages, exchange rates, production, and international trade flows. We divide the data from each experiment into two segments of equal length, and designate the two segments as the early and the late periods of the experiment. For experiment 1, the early and late periods comprise periods 1-6 and 7-12, respectively. In experiments 2 and 3, the early and late periods correspond to periods 1-8 and 9-16, respectively. For price variables: output prices, wages and exchange rates, the 
normalized standard deviation is defined as $\sigma_{i m}{ }^{L} / \mu_{i m}{ }^{L}$, where $\sigma_{i m}{ }^{L}$ is the standard deviation of all transaction prices in market $m$ during the late periods of experiment $i$, and $\mu_{i m}{ }^{L}$ is the average transaction price in the late periods of experiment $i . \sigma_{i m}{ }^{E}$ and $\mu_{i m}{ }^{E}$ are analogous variables for the first half (the early periods) of the experiments. For trade flows and production, the same variables are calculated, although the total quantity imported or produced in each period is the unit of observation, rather than the individual transaction.

We say that reduced variability is occurring in a market if $\sigma_{i m}{ }^{L} / \mu_{i m}{ }^{L}<\sigma_{i m}{ }^{E} / \mu_{i m}{ }^{E}$, that is, if the normalized standard deviation is lower in the late periods than in the early periods. We say that the economy as a whole exhibits reduced variability if (a) the percentage of market prices that exhibit reduced variability is significantly greater than $50 \%$, and (b) the percentage of market quantity variables that exhibit reduced variability is significantly greater than $50 \%$. To test for reduced variability we use a sign test of the hypothesis that the median value of $\sigma_{i m}{ }^{L} / \mu_{i m}{ }^{L}-\sigma_{i m}{ }^{E} / \mu_{i m}{ }^{E}$, over the relevant variables, is greater than or equal to zero. If the hypothesis is rejected it means that a significant majority of the variables is exhibiting reduced variability and therefore that the economy is exhibiting reduced variability.

Convergence occurs when prices are closer to the competitive equilibrium values in late periods than in early periods. We will say that convergence of a variable occurs if the inequality $\left|\mu_{i m}{ }^{L}-m_{i}{ }^{*}\right|<\left|\mu_{i m}{ }^{E}-m_{i}{ }^{*}\right|$ holds, where $m_{i}{ }^{*}$ denotes the competitive equilibrium prediction of variable $m$ in experiment $i$. As with stabilization, we say that an economy is converging if a significant majority of both price and quantity variables exhibit convergence.

For any variable that exhibits equilibration we can estimate the exact value to which the variable would converge asymptotically if the data in the experiment were extrapolated into the infinite future. Even if equilibration is observed and the variables move in the direction of their equilibrium values, it is possible that they converge asymptotically to values other than those of equilibrium. To estimate these values, we use the model in equation (10), first employed in Noussair et al. (1995). The equation is a natural specification for panel data where there is heterogeneity between the data series at the beginning of the time horizon the data covers, but where the dependent variable converges to a common asymptote near the end of the time horizon, a common pattern in experimental studies of markets.

$$
y_{i t}-y_{i}^{*}=\beta_{11} \frac{D_{1}}{t}+\beta_{12} \frac{D_{2}}{t}+\beta_{13} \frac{D_{3}}{t}+\beta_{2} \frac{t-1}{t}
$$

In the above equation, $y_{i t}$ denotes the value of one of the variables in the economy in period $t$ of the $i$ th experiment, and $y_{i}{ }^{*}$ is the competitive equilibrium value of the variable. $y_{i}{ }^{*}$ has no index for time because the competitive equilibrium predictions remain the same over time within an experiment, although they differ between experiments. $D_{i}$ is a dummy variable for experiment $i$ and $t$ denotes the time period within the experiment. For example, $D_{i}$ equals 1 if the data are from experiment $i$. The model allows for the estimation of the value of the dependent variable at the beginning of each horizon and the value to which the series is converging. In the first period of experiment $i, D_{i} / t=1$ and all of the other variables equal 0 . Therefore, $\beta_{11}$ is the estimated 
value of the time series at the beginning of experiment 1 , and $\beta_{12}$ and $\beta_{13}$ are analogous. In later periods of experiment $i$ the $D_{i} / t$ term decreases toward 0 , while the variable $(t-1) / t$ increases toward 1. If $t$ were projected to the infinite future, $(t-1) / t$ would converge to 1 . Therefore $\beta_{2}$ can be interpreted as the asymptote to which the time series is converging. We will refer to the $\beta_{2}$ estimate as the convergence value of the variable. The specification assumes that there is a common value to which the time series is converging for all experiments. We will say that we cannot reject the hypothesis that a variable converges to its competitive equilibrium value if the estimated $\beta_{2}$ is not significantly different from zero. The standard errors are corrected for heteroscedasticity to account for stabilization, which would decrease the variance of the error terms for later periods in the sessions.

\section{Results}

\subsection{The equilibration hypothesis}

Figures $4-6$ illustrate the price patterns observed in experiment three, which are typical for the three economies we studied. Figure 4 shows the average transaction prices for the three outputs during each period in each of the three countries in experiment three in comparison with the competitive equilibrium prices, shown in bold horizontal lines. Figure 5 contains the analogous data for input prices. Figure 6 illustrates the average exchange rate, as well the competitive equilibrium exchange rate, and the level that would be consistent with Purchasing Power Parity given the actual average prices in the three countries. It is apparent from the figures that the values of many of the variables differ substantially from the competitive equilibrium levels. For example, the price of $z$ in country $B$ is roughly $50 \%$ higher than the competitive equilibrium level for most of the experiment. The prices of $y$ and $z$ in country $C$ are higher than the equilibrium by similar percentages. The exchange rate of currency $C$ to $A$ is roughly $40 \%$ higher than the predicted rate of 5.17. However, the time series also suggest that many of the variables are closer to the equilibrium levels in the late periods than in the early periods, suggesting that equilibration, as defined in section 1, may be taking place. For example, in country $\mathrm{C}$, the prices of $k, x, y$, and $z$ are noticeably closer to their equilibrium levels in the late periods of the experimental session than early on. The same is true for $k$ and $x$ in country B. Result 1 and its supporting discussion summarize the balance of the evidence on equilibration in our data.

\section{[Figures 4-6: About Here]}

\section{Result 1: The equilibration hypothesis is supported.}

Support for result 1: Table 3 contains the competitive model predictions for each of 23 system level variables in the experiment. In addition, the competitive equilibrium implies a level of production of each good in each country, yielding predictions for 9 more variables. Since there are three independent experiments, these data make up 96 time series. The equilibration hypothesis asserts that (a) the variance in the variables of the economy declines over time (reduced variability) and (b) the variables attain values closer to the equilibrium over time (convergence). Operationally, as described in section three, we define an economy to be equilibrating if significantly more than $50 \%$ of the 
price and quantity variables exhibit declining variance and means closer to the competitive equilibrium in the late periods than in the early periods.

We find that reduced variability is occurring in the experimental economies. $\sigma_{i m}{ }^{L} / \mu_{i m}{ }^{L}<\sigma_{i m}{ }^{E} / \mu_{i m}{ }^{E}$ for 23 of 27 output prices (3 outputs*3 countries*3 experiments), 15 of 18 wage rates, 5 of 6 exchange rates, 17 of 18 trade variables (IMP ${ }_{m}^{J}$ quantities) and 24 of 27 production variables. In other words, 43 of 51 prices and 41 of 45 quantities are exhibiting reduced variability. We reject at $p<.01$ the hypothesis that $50 \%$ or less of the price variables are exhibiting reduced variability as well as the hypothesis that $50 \%$ or less of the quantity variables are exhibiting reduced variability at the same level of significance.

Convergence is also occurring. Prices, wages, exchange rates, production, and magnitudes of international trade are closer to the equilibrium predictions late in the sessions than early in the sessions. The inequality $\left|\mu_{i m}{ }^{L}-p_{i m}{ }^{*}\right|<\left|\mu_{i m}{ }^{E}-p_{i m}{ }^{*}\right|$, where $p_{i m}{ }^{*}$ denotes the competitive equilibrium price, holds for 20 of 27 output prices, 13 of 18 input prices, and 5 of 6 exchange rates. The inequality $\left|\mu_{i m}{ }^{L}-q_{i m}{ }^{*}\right|<\left|\mu_{i m}{ }^{E}-q_{i m}{ }^{*}\right|$, where $q_{i m}{ }^{*}$ denotes the competitive equilibrium quantity, is satisfied for 17 of 18 international trade flow variables, and 17 of 27 production variables. Thus, for 41 of 51 prices and 34 of 45 quantities, convergence is occurring. We reject the hypotheses that $50 \%$ or fewer of the prices (at $p<.01$ ) and that $50 \%$ or fewer of the quantities (at $p<.05$ ) are converging. Therefore, convergence is also taking place in the economies. $\square$

Thus, although the pattern is less obvious than in previous experimental studies of simpler economies, there exists evidence that the economic variables are closer in the late periods than in the early periods to a common attractor, their equilibrium values. They also exhibit less variation in the late than in the early periods. A natural question arises about what patterns might be observed if the experiment were conducted over a much longer horizon. In particular, would the variables in the economy converge to and not merely toward their equilibrium values? We consider this issue with estimation of equation (10), which can provide estimates of the precise values toward which the data series are converging if extrapolated into the infinite future. The particular equation seems to be a reasonable specification to capture the structure of the data in light of the presence of reduced variability and convergence. The estimated coefficients for output prices are shown in table 4. The estimates of the same model for input prices and exchange rates are given in table 5. Those for imports of goods into each of the three countries and the production of each country are in table 6.

\section{[Tables 3 - 5: About Here]}

The tables show that many of the convergence values, described by the $\beta_{2}$ coefficients, are significantly different from zero, indicating that even if we extrapolate our data to the distant future, we cannot conclude that they converge asymptotically to values precisely equal to the competitive equilibrium. Thus, assuming the convergence process follows the structure of (10), there appears to be some degree of deviation from the competitive equilibrium, even in the long run. This is consistent with the visual impression gained from observation of figures $4-6$. Nevertheless, the regressions support the notion that an equilibration process, albeit incomplete, is taking place in the 
economy. The $\beta_{2}$ coefficients are closer to zero than the $\beta_{1 j}$ coefficients for 16 of 27 output prices (where each comparison is between a $\beta_{2}$ and one of the $\beta_{1 j}$ coefficient from the same estimated equation), 12 of 18 wages, and 6 of 6 exchange rates. The convergence is more evident for quantities transacted. For 15 of the 18 import variables and 21 of the 27 production variables, $\beta_{2}$ is closer to zero than the corresponding $\beta_{11}, \ldots$, $\beta_{13}$ terms. The result that convergence in the direction of equilibrium is stronger for quantities than for prices is consistent with results obtained in the simpler international economies studied by Noussair et al. $(1995,1997)$. The production variables have $\beta_{2}$ coefficients greater than the corresponding $\beta_{1 j}$ terms in 26 of 27 instances indicating that output is increasing over time. ${ }^{11}$

\subsection{Properties of the equilibration process}

In this subsection we conduct an exploratory analysis of the production, trade and price data, and study the empirical characteristics of the equilibration process in our economies. We investigate whether the equilibration process is characterized by consistent and regular dynamics. The regressions in tables 4 - 6 reveal several interesting patterns about the nature of the equilibration process. The first pattern is that the estimated $\beta_{2}$ coefficients tend to deviate from the equilibrium in the direction of autarky. Under autarky, the prices of the goods that would be exported under free trade, $x^{A}, y^{B}$ and $z^{C}$, are lower than in the competitive equilibrium, and the quantity of these goods produced is below the competitive equilibrium level. The output prices and quantities produced for the remaining six outputs are higher in autarky than in the competitive equilibrium. The import variables are all equal to zero in autarky and positive in the competitive equilibrium. The convergence values tend to lie between the competitive equilibrium and the autarky levels. This pattern is similar to the home bias often noted in the study of field data, since it reveals the presence of lower international trade than the fundamentals of the economies would predict even when taking into account transportation costs, tariffs, and other measurable variables, as well as the price patterns characteristic of a home bias. We will refer to the tendency of the economies to deviate from their equilibria in the direction of autarky as the home bias property.

\section{Property 1: The Home Bias Property - A home bias in trade exists. Observed trade and production levels deviate from competitive model predictions in direction of autarky.}

Support for property 1: All of the $\beta_{2}$ coefficients in table 5 for the variables indicating import quantities and the location of the production of the three goods differ from zero in the direction of autarky. The levels of imports are all lower than in the competitive equilibrium, as are the levels of production of the goods that a country exports (the variables $\left.\operatorname{Prod}_{x}^{A}, \operatorname{Prod}_{y}{ }^{B}, \operatorname{Prod}_{z}{ }^{C}\right)$. All of the other production levels are greater than in

\footnotetext{
${ }^{11}$ We can measure the amount of the increase in output that is due to increasing factor utilization by producers and the amount that is due to productivity increases (increasing output per unit of input), by calculating a version of the Solow (1957) residual, which is the component of increased output that greater utilization of factors cannot explain. Factor utilization in the economy increases by an average of $14.14 \%$ per period from periods 1 to 3 and .58\% per period thereafter. Productivity increases by an average of $7.87 \%$ per period from periods 1 to 3 and $.65 \%$ per period thereafter.
} 
the competitive equilibrium, indicating that more production of these goods for domestic consumption occurs than predicted. Six of eight $\beta_{2}$ coefficients for output prices deviate from the competitive model in the direction of autarky $\left(p_{y}{ }^{B}\right.$ is not significantly different from the competitive level at the $5 \%$ level of significance).

This "Home Bias Puzzle" has given rise to many alternative theories to explain why there is less international trade than theory predicts. ${ }^{12}$ Among those explanations are imperfect contract enforcement (Anderson and Marcouiller, 1999,) differences in legal systems (Turrini and Van Ypersele, 2001,) intermediate goods trade (Hillberry and Hummels, 2002,) and information/networks (Rauch, 2001.) While these explanations may be plausible for accounting for the field data, none of these are factors in our laboratory experiments. In the experiments, convergence toward the general equilibrium takes place from the direction of autarky, which corresponds to $100 \%$ home bias. Thus, a slow or incomplete adjustment to equilibrium would retain a lingering property of home bias. Furthermore, if a change in the underlying environment moved the equilibrium toward increased international trade, a less than instantaneous equilibration process would also have the home bias property.

One might be tempted to think that the cash-in-advance constraint accounts for the home bias in our economies. However, any experimental design will have some agents engaging in international trade having to make a sequence of decisions. That is, decisions about how much of a good to buy and sell and at what price must be made at a different point in time than the decision about how much foreign exchange to buy or sell and at what exchange rate. This creates inherent risk in foreign transactions that does not exist for domestic transactions. We believe that it is this risk that creates "home bias" and will be part of the environment no matter how the mechanics of the foreign exchange are structured. We also suspect that this type of risk is present not only in our experimental environment, but also in field economies.

Property 1 concerns the quantities of goods traded in our economies. Properties 2 and 3 below describe the behavior of transaction prices. We have already noted that prices tend to deviate from the Competitive Model predictions in the direction of autarky. However, in addition to the mean prices following a particular pattern relative to the equilibrium level, we also find that the variances in input and output prices exhibit consistent patterns. These are summarized as property 2. The normalized standard deviations of transaction prices are generally greater for input than for output prices. This

\footnotetext{
${ }^{12}$ Home bias in field data has been carefully documented in McCallum (1995) for example. McCallum’s work points to a very large border effect so that the spatial location of trade matters a great deal. He finds that trade between two Canadian provinces is more than twenty times larger than trade between one of the provinces and a US state of similar size and distance. However, in our experimental world there is no spatial element and no borders. So, the home bias we find in our data cannot be due to border effects. Anderson (2000) surveys recent empirical work on the existence of home bias in international trade in commodities and concludes that, "The evidence points to very large missing transactions costs of international trade." He then suggests possible sources of transaction costs that include information costs, imperfect contract enforcement, insecurity, and non-diversifiable risks. In our laboratory environment, the information is the same for domestic and foreign purchases, contract enforcement and security are not issues and the type of risk considered by Anderson does not arise in our environment. So, our finding of home bias suggests that the missing transactions costs may be due, at least in part, to the out-of-equilibrium dynamics of market convergence, in addition to those causes postulated in the literature.
} 
is consistent with empirical studies of field data (see for example, Clark 1999) that find that prices for primary and intermediate goods, as measured by the Producer Price Index, tend to be more volatile than for final goods, measured by the Consumer Price Index. Furthermore, normalized standard deviations also tend to be greater for exchange rates than for either input or output prices. The volatility of exchange rates has been a topic of interest in international finance. It has been noted that changes in exchange rates are not fully reflected in prices of goods in different countries, leading to failures of the Law of One Price and of Purchasing Power Parity (see for example Obstfeld and Rogoff, 2000). In our data we also find that exchange rates tend to be more volatile than other prices.

\section{Property 2: The Input/Output/Exchange Price Variance Property - Transaction price variability is higher for producer (input) prices than for consumer (output) prices. Exchange rates exhibit more variability than the prices in other markets.}

Support for property 2. To provide a measure of the volatility of consumer prices, we calculate the pooled average normalized standard deviation across the two input markets in each country. This is given by $\frac{\sigma_{\text {inputs }}^{J}}{\mu_{\text {inputs }}^{J}}=\sqrt{\left(\left(\left(n_{l}{ }^{J}-1\right)\left(\sigma_{l}^{J}\right)^{2}\right) / \mu_{l}^{J}+\left(\left(n^{J}{ }_{k}-1\right)\left(\sigma_{k}^{J}\right)^{2}\right) / \mu_{k}^{J}\right) /\left(n_{l}{ }^{J}+n_{k}{ }^{J}-2\right)}$, where $n_{m}{ }^{J}$ is the number of units of input $m$ traded in country $J$. We calculate as well the pooled average normalized standard deviation over the three output markets in each country, which is given by $\frac{\sigma_{\text {outputs }}^{J}}{\mu_{\text {outputs }}^{J}}=\sqrt{\left(\left(\left(n_{x}{ }^{J}-1\right)\left(\sigma_{x}^{J}\right)^{2}\right) / \mu_{x}^{J}+\left(\left(n_{y}{ }^{J}-1\right)\left(\sigma_{y}^{J}\right)^{2}\right) / \mu_{y}^{J}+\left(\left(n_{z}{ }^{J}-1\right)\left(\sigma_{z}^{J}\right)^{2}\right) / \mu_{z}^{J}\right) /\left(n_{x}{ }^{J}+n_{y}{ }^{J}+n_{z}{ }^{J}-3\right)}$

We consider the late periods of each experiment. In experiment 1 , the pooled normalized standard deviation of prices in the input markets is greater than that of output markets in each of the three countries. In experiments 2 and 3, the input markets exhibit greater pooled normalized standard deviations than the output markets in 2 of the 3 countries. Thus, in seven of nine possible cases, there is more variability in national producer prices than in consumer prices.

We also calculate the pooled average normalized standard deviation of prices in the late periods in the currency markets and compare them to those of prices in the six world input markets (two markets in each country) and the nine world output markets. In each of the three experiments, the normalized standard deviation of prices is greater in the currency markets than in the input markets as well as in the output markets.

Thus, it appears that input and output markets behave differently in some respects from each other and from foreign exchange markets. The greater price variance in input than in output markets may reflect a relatively slow speed of adjustment of markets, such as factor markets, where demand is derived rather than exogenous as in the output markets. Such a principle is consistent with the high variance observed in exchange rates, since demand for foreign exchange is also derived. The markets tend to stabilize "backwards", beginning with the final goods market, and followed by input markets. 
Thus, a version of the "Swingback Hypothesis" (Forsythe et al. 1982), observed in experimental asset markets, appears to be at work in our economies. ${ }^{13}$

Markets for foreign exchange are of special interest to economists. It has been noted in field studies that exchange rates exhibit persistent departures from purchasing power parity levels. As the support of property 3 documents, there are deviations from purchasing power parity in our data as well, but they tend to diminish over time. Figure 6 illustrates this pattern, and shows that during the convergence process exchange rates track ever more closely over time the level that corresponds to Purchasing Power Parity, the exchange rate that would equalize purchasing power in the two countries. We define $r_{B}^{p p p}$, the Purchasing Power Parity exchange rate, as the following:

$$
r_{B}^{P P P}=\frac{p_{x}^{B} \sum_{j} x_{j}+p_{y}^{B} \sum_{j} y_{j}+p_{z}^{B} \sum_{j} z_{j}}{p_{x}^{A} \sum_{j} x_{j}+p_{y}^{A} \sum_{j} y_{j}+p_{z}^{A} \sum_{j} z_{j}}
$$

The weighted output price averages for each country in the numerator and the denominator of (11) use the actual world production (which is always equal to world consumption) of each good as the weight for the good in the consumption bundle $(j$ indexes the country). In our data, we find that the exchange rates tend to converge toward the PPP level, even when the PPP level departs from the competitive equilibrium. Although the output markets might be in disequilibrium, the currency market prices adjust in the direction of equalizing purchasing power in the two countries. While the movement of exchange rates is toward PPP, this convergence is not complete even asymptotically. As table 6 reveals, the exchange rate of currency $C$ for A does not reach the PPP level. Of course, since prices in the goods markets are not at equilibrium levels in all markets, the Law of One Price will fail to hold for some goods.

\section{Property 3: Purchasing Power Parity Convergence - Exchange rates tend to move in the direction of purchasing power parity levels. However, convergence is incomplete and purchasing power parity is not reached.}

Support for property 3: Table 6 contains the regression results for the variable $\left(r_{A}\right.$ $\left.r_{A}^{P P P}\right)$ and $\left(r_{B}-r_{B}^{P P P}\right)$. For both variables, the $\beta_{2}$ terms are closer to zero that any of the other three coefficients. For the variable $r_{B}-r_{B}^{P P P}$, the $\beta_{2}$ term is not significantly different from zero. However, the $\beta_{2}$ term for $r_{A}-r_{A}{ }^{P P P}$ is significantly different from zero at the $p<.05$ level.

\section{[Table 6: About Here]}

Property 4 encompasses two characteristics of prices of final goods. The first is that final goods prices tend to be greater than the competitive model predictions. This is consistent with previous experimental work on multiple-market economies (Goodfellow

\footnotetext{
${ }^{13}$ In repeated markets for two-period assets, the final period transaction price tends to converge to near its rational expectations equilibrium price before the first period transaction price does.
} 
and Plott, 1990; Noussair et al., 1995). The second is that the greater consumer surplus is, relative to the competitive equilibrium revenue in the market, the farther the average transaction price is above the competitive prediction. Since all market demand curves for final goods in our economies are linear, the statement is equivalent to the assertion that the steeper the demand function, holding the competitive equilibrium price and quantity constant, the more the price exceeds the competitive prediction. This pattern is somewhat reminiscent of the rent asymmetry effect studied by Smith and Williams (1982). They note that prices in single market economies tend to converge to equilibrium prices from above when equilibrium consumer surplus exceeds producer surplus, and from below when producer surplus is greater than consumer surplus. In essence, prices in our markets are higher relative to equilibrium prices when they have upward flexibility, that is, when high prices have relatively small consequences on the quantity exchanged.

\section{Property 4: The Surplus Price Adjustment Property for Final Goods - Output prices are higher than in the competitive equilibrium. The difference between observed and equilibrium output prices tends to be greater, the greater the ratio of consumer surplus to equilibrium expenditure.}

Support for property 4: Table 3 shows that for eight of the nine outputs in the economy, the convergence value is positive and for seven of nine it is significantly positive, indicating that output prices tend to converge to levels greater than competitive equilibrium values. We compare the correlation between the following two variables for each good in each country (nine total goods). The first variable $\operatorname{is}\left(\int_{0}^{q_{m}^{J}}\left(D_{m}^{J}\right)^{-1}\left(q_{m}^{J}\right)-p_{m}^{*_{J}^{J}} d q_{m}^{*_{J}}\right) /\left(p_{m}^{*_{m}^{J}} q_{m}^{*_{m}^{J}}\right)$, the ratio of competitive equilibrium consumer surplus to competitive equilibrium expenditures for good $m$ in country $J$. The second is $p_{m}{ }^{J} / p_{m}{ }^{J}$, the ratio of the observed to the equilibrium price of good $m$ in country $J$. $q_{m}^{J}$ denotes the quantity of $m$ sold in country $J$ and $q_{m}^{*_{m}^{J}}$ is the corresponding equilibrium quantity. $p_{m}^{J}$ is the observed price of $m$ sold in $J$ and $p{ }^{*}{ }_{m}^{J}$ denotes the equilibrium price. The observed price is defined by adding the estimated value of $\beta_{2}$ in table 3 to the equilibrium price, so that $p_{m}{ }^{J} / p_{m}{ }^{J} *=\frac{p_{m}^{J} *+\beta_{2}}{p_{m}^{J} *}$. We rank the nine goods (three goods in three countries) by their values of the two variables, which are pooled across sessions, and calculate the correlation between the two rankings. The correlation between the two rankings is .636. Furthermore, the goods $p_{x}{ }^{C}, p_{x}{ }^{B}$, and $p_{y}{ }^{C}$ have the first, second, and third highest values of both variables, and $p_{x}{ }^{A}$ has the lowest value of both variables. The ratio of consumer surplus to competitive equilibrium expenditure and the observed percentage that the price exceeds the equilibrium level are highly positively correlated.

Property 5 is a relationship between output and input prices that was previously observed in other experimental studies (Noussair et al., 1995; Hey and di Cagno, 2000; Riedl and van Winden, 2001). The relationship also appears here. Noussair et al. observed that the ratio of input to output prices was below the competitive equilibrium ratio in their data. They explained the deviation from the competitive equilibrium ratios 
as a compensation for a risk that producers undertook, and they referred to the price pattern as the Risk Compensated Input/Output Price Adjustment Property. The source of the risk lies in the fact that producers must commit themselves to purchase inputs that have no value other than in the irreversible production of an output to be sold later at a price that is unknown at the time of the input purchase. To compensate for the risk they bear, producers earn a premium over the amount they would earn in the competitive equilibrium. We find that the property generalizes in a straightforward way to the economies studied here, although not quite as consistently. This risk premium, along with the inefficiencies in production arising from the misallocation of input between firms and suboptimal input mixes within firms, appears to account for the fact that output prices exceed the competitive predictions.

\section{Property 5: The Risk Compensated Input/Output Price Adjustment Property - Wage/Price ratios are lower than the competitive equilibrium level.}

Support for property 5: The existence of three outputs and two inputs in each of three countries define six ratios of wages to prices within a country and a total of 18 in the economy. Over the three experiments there are 54 ratios of the form $w_{m}{ }^{J} / p_{n}{ }^{J}$. Over the course of an experiment, 33 of 54 ratios (61.1\%) have an average value lower than the competitive equilibrium level, and in the late periods (the second half of the life of the economies), 37 of 54 (68.5\%) have an average value lower than the equilibrium ratio.

The final property of the equilibration process presented here is a behavioral regularity that has been observed in some previous experimental studies, the Sawtooth property of transaction prices (see Plott 2002 for a detailed discussion). The Sawtooth property is a characteristic of the time series of transaction prices in a goods market within a period. Here the pattern appears to manifest itself with much greater force than in simpler experimental economies. In almost all markets for both outputs and inputs, and in all of the experiments, prices are declining within a market period.

Property 6: The Sawtooth Property - Within a market period, input and output markets exhibit the "sawtooth" property. Transaction prices decline within the period. This pattern is consistent with the existence of a higher option value for goods acquired earlier in the period.

An example is shown in figure 7. We believe that declining prices within periods in these markets (resale of units purchased is permitted in any of the markets) occurs at least in part because the option of resale later in the period increases the value of units obtained early in the period. The observation that the Sawtooth Property does not appear in our foreign exchange markets supports this interpretation. Unlike in an input or an output market, the option value of resale of foreign currency exists for both parties to the transaction. Each party to a foreign exchange transaction is a "purchaser" of a "good", a foreign currency (domestic currency can be thought of as the money used to purchase the good), which has more value when acquired earlier in the market period. The premia resulting from the option value of resale for the two parties may thus have a tendency to offset, and the result is the absence of the Sawtooth pattern in the currency markets. 
[Figure 7: About Here]

\section{Conclusions}

Experimental economics has produced a growing body of evidence supporting a principle of market convergence toward the equilibrium of the competitive model. The competitive equilibrium is defined as a solution to a system of simultaneous equations and is thus a static concept. However, the equilibration process is dynamic and is influenced by human behavior resulting from bounded rationality, heterogeneous beliefs, learning and errors. These uncontrolled features of behavior interact with technological and institutional constraints such as irreversible production, cash-in-advance constraints, undiversifiable risk, and the particular institutions of exchange in effect, to produce a dynamic process of activity over time. Our understanding of this convergence process is empirical so a natural question exists about the robustness of the stylized facts of market convergence.

The research reported here created an economic system far larger and more complex than anything studied experimentally in the past and focused on three issues. The first is the robustness of the most basic principles of market behavior to matters of scale. We consider whether behaviors observed in small-scale laboratory economies are also observed at a larger, more complex scale. Are larger scale economies orderly and similar to smaller scale versions or does chaos ensue with scale? Do new and different principles emerge to govern system behavior or do the same principles observed operating in smaller economies still apply?

Our data demonstrate that chaos does not necessarily ensue as the complexity of the economy increases. An equilibration process is clearly evident in the sense that the movements of economic variables are in the direction of the general competitive equilibrium of the appropriate model together with decreasing variance. Although the equilibration process is slower and less complete than in simpler economies, there are no qualitative differences. The same principles are in operation at both scales.

The second issue is the reliability of the competitive model as developed to deal with the particular production, preference, and market interdependencies that are characteristic of international economies. We conclude that the essential elements of the special version of competitive theory that has evolved to address complex issues of international trade and finance are operating. The general equilibrium model in the form of a classical theory of international economics predicts much of what is observed. In the sense of the movement of magnitudes of variables such as trade flows and exchange rates, the general theory of international trade and finance emerges with much supporting evidence.

Our experiments contribute to a third issue. We ask whether empirical patterns frequently observed in field settings appear in the experiments. If such patterns are observed, it demonstrates that explanations of field events are not forced by logic to special institutions, parameters, or theories, for explanations of what they have observed. The theoretical principles of the general equilibrium model coupled with the properties of the market equilibration process may provide appropriate explanations in some cases. Indeed, some well-known empirical patterns typically found in data from field studies of international trade and finance are also found in the experimental data. Exchange rates 
and prices converge toward purchasing power parity levels, though not completely. Exchange rates exhibit proportionally more variance than input or output prices. The variance of input prices exceeds that of output prices. A home bias in trade is observed. That is, accounting for transportation costs, tariffs and other measurable variables, there is significantly less international trade than theory predicts.

At least in our economies, the above properties appear to be properties of the equilibration process as opposed to consequences of special institutions, policy variables or technological change. Of course, our findings do not imply that patterns observed in field data are not affected by shocks or policy, but they do raise the possibility that the patterns observed in the field are characteristics of the process of market equilibration of international economies. In principle, the methodology we have used here, the exploration of the laboratory data for patterns that appear in field data, may be successfully applied in reverse. In particular, the empirical patterns observed in experiments might be used to motivate conjectures about patterns of field data produced in naturally occurring economies.

We close with the conjecture that the patterns of convergence we observe in our experiments will be observed operating at much larger scales than we were able to create for this study. We saw nothing about the operation of these economies that would suggest that the basic principles of economic behavior would be severely modified by scale. The results reported here suggest that much larger market systems are beyond neither the human capacities of participants in the economies nor beyond the reach of laboratory experimental methods.

\section{References}

Anderson, J. (2000) “Why Do Nations Trade (So Little)?” Pacific Economic Review, 5, pp. 115-134.

Anderson, J. and D. Marcouiller (1999) “Trade, Insecurity, and Home Bias: An Empirical Investigation” mimeo, revision of NBER working paper \#7000.

Anderson, C., S. Granat, C. Plott and K. Shimomura (2003) "Global Instability in Experimental General Equilibrium: The Scarf Example,” Journal of Economic Theory, forthcoming.

Bossaerts, Peter, Charles R. Plott and Daniel Kleiman, "Price Discovery in Financial Markets: The Case of the CAPM,” in Charles R. Plott, Information, Finance and General Equilibrium. Collected Papers on the Experimental Foundations of Economics and Political Science, Volume 3: Cheltenham, UK: Edward Elgar Publishing (2001): 44592.

Clark, T. (1999), “The responses of Prices at Different Stages of Production to Monetary Supply Shocks,” Review of Economics and Statistics, 81, pages 420-433.

Fisher, E., and F. Kelly (2000), "Experimental Foreign Exchange Markets”, Pacific Economic Review, Vol. 5. pages 365-388. 
Forsythe, R., T. Palfrey and C. Plott (1982), “Asset Valuation in an Experimental Market”, Econometrica, pages 537-567.

Forsythe, R., T. Palfrey and C. Plott (1984) "Futures Markets and Informational Efficiency: A Laboratory Examination,” Journal of Finance 39, pages 955-981

Goodfellow J. and C. Plott (1990), “An Experimental Examination of the Simultaneous Determination of Input Prices and Output Prices”, Southern Economic Journal, 56, pages 969-983.

Hey, J, and D. DiCagno (1998), “Sequential Markets: An Investigation of Clower's Dual Decision Hypothesis”, Experimental Economics, 1, pages 63-85.

Hillberry, R. and D. Hummels, (2002), "Explaining Home Bias in Consumption: The Role of Intermediate Input Trade,” mimeo.

Lian, P. and C. Plott (1998), “General Equilibrium, Markets, Macroeconomics and Money in a Laboratory Experimental Environment,” Economic Theory 12(1): pages 2175.

McCallum, J. (1995) “National Borders Matter: Canada-US Regional Trade Patterns”, American Economic Review 85(3), pages 615-623.

Noussair, C., C. Plott and R. Riezman (1995) “An Experimental Investigation of the Patterns of International Trade”, with Charles Plott and Raymond Riezman, American Economic Review, June 1995, pages 462-491.

Noussair, C., C. Plott and R. Riezman (1997) “The Principles of Exchange Rate Determination in an International Finance Experiment”, with Charles Plott and Raymond Riezman, Journal of Political Economy, August 1997, pages 822-862.

Obstfeld, M. and K. Rogoff (2001) “The Six Major Puzzles in International Finance: Is There a Common Cause”, NBER Macroeconomics Annual, 15 (2000).

Plott (2002), Properties of Disequilibrium Adjustment in Double Auction Markets, Handbook of Experimental Economic Results, C. Plott and V. Smith, eds. Forthcoming

Plott, C. "Research on Pricing in a Gas Transportation Network.” Office of Economic Policy Technical Report no. 88-2. Federal Energy Regulatory Commission, Washington, D.C., July 1988.

Plott, C. "Market Stability: Backward Bending Supply in a Laboratory Experimental Market.” Economic Inquiry 38, no. 1 (2000): 1-18. 
Plott, C. "Equilibrium, Equilibration, Information and Multiple Markets: From Basic Science to Institutional Design.” Nobel Symposium on Behavioral and Experimental Economics, Stockholm, Sweden. December 4, 2001.

Plott, C. and J. Goodfellow, "An Experimental Examination of the Simultaneous Determination of Input Prices and Output Prices," Southern Economics Journal 56 (April, 1990):969-983.

Plott, C. and G. George, "Externalities and Corrective Policies in Experimental Markets.” Economic Journal 93 (March 1983):106-127. Reprinted in Recent Developments in Experimental Economics, vol. 2, no. 11, pp. 179-200, edited by J. D. Hey and G. Loomes. Edward Elgar Publishing Ltd, U.K., 1993.

Plott, C. and Glen George, "Marshallian vs. Walrasian Stability in an Experimental Market,” Economic Journal, (May 1992): 437-460.

Plott, C. and Jared Smith, "Instability of Equilibria in Experimental Markets: UpwardSloping Demands, Externalities, and Fad-Like Incentives,” Southern Economic Journal 65(3), January 1999:405-426.

Plott, C. and Shyam Sunder, "Rational Expectations and the Aggregation of Diverse Information in Laboratory Security Markets”, Econometrica 56 (September 1988): 10851118.

Rauch, J. (2001), “Business and Social Networks in International Trade,” Journal of Economic Literature, 34, 1177-1203.

Riedl, A. and van Winden, F. (2001) 'Does the Wage Tax System cause Budget Deficits?' Public Choice 109, 371-394.

Smith V. and A. Williams (1982), "The Effect of Rent Asymmetries in Experimental Double Auction Markets”, Journal of Economic Behavior and Organization, pages 99116.

Solow, R. (1957) “Technical Change and the Aggregate Production Function”, Review of Economics and Statistics, 39(3), pages 312-320.

Trefler, D. (1995) “The Case of the Missing Trade and Other Mysteries” American Economic Review, 85(5), pages 1029-1046.

Turrini, A. and T. Van Ypersele (2001), “Traders, Courts, and the Home Bias Puzzle,” mimeo.

Williams, A., V. Smith, J. Ledyard, J., and S. Gjerstad (2000), "Concurrent Trading in Two Experimental Markets with Demand Interdependence” Economic Theory, 16(3), pages $511-528$. 
Table 1: Number of Participants of Each of the Twelve Types and Their Functions

\begin{tabular}{|c|c|c|c|c|c|c|}
\hline Type & Country & Role & Parameter Values & $\begin{array}{l}\# \quad \text { in } \\
\text { exp } 1\end{array}$ & $\begin{array}{l}\# \text { in } \\
\exp 2\end{array}$ & $\begin{array}{l}\# \text { in } \\
\exp 3\end{array}$ \\
\hline 1 & A & $\begin{array}{l}\text { Producer of X } \\
\text { Consumer of Y }\end{array}$ & $\begin{array}{l}f_{x}^{A}(k, l)=4 l^{25} k^{.25} \\
U(y)=1650 y-100 y^{2}\end{array}$ & 5 & 3 & 5 \\
\hline 2 & A & $\begin{array}{l}\text { Producer of } \mathrm{Y} \\
\text { Consumer of } \mathrm{X} \text { and } \mathrm{Z}\end{array}$ & $\begin{array}{l}f_{y}^{A}(k, l)=2 l^{25} k^{.25} \\
U(x, z)=700 x-100 x^{2}+1900 z- \\
100 z^{2}\end{array}$ & 5 & 3 & 5 \\
\hline 3 & A & $\begin{array}{l}\text { Producer of } \mathrm{Z} \\
\text { Consumer of } \mathrm{X} \text { and } \mathrm{Y}\end{array}$ & $\begin{array}{l}f_{z}^{A}(k, l)=2 l^{25} k^{25} \\
U(x, y)=700 x-100 x^{2}+1650 y- \\
100 y^{2}\end{array}$ & 5 & 3 & 4 \\
\hline 4 & A & $\begin{array}{l}\text { Supplier of } \mathrm{L} \text { and } \mathrm{K} \\
\text { Consumer of } \mathrm{Z}\end{array}$ & $\begin{array}{l}C(l, k)=26 l+2 l^{2}+10 k+5 k^{2} \\
U(z)=1900 z-100 z^{2}\end{array}$ & 5 & 3 & 5 \\
\hline 5 & B & $\begin{array}{l}\text { Producer of } \mathrm{X} \\
\text { Consumer of } \mathrm{Y} \text { and } \mathrm{Z}\end{array}$ & $\begin{array}{l}f_{x}^{B}(k, l)=2 l^{25} k^{.25} \\
U(y, z)=3900 y-400 y^{2}+5600 z \\
-400 z^{2}\end{array}$ & 5 & 4 & 5 \\
\hline 6 & B & $\begin{array}{l}\text { Producer of Y } \\
\text { Consumer of X }\end{array}$ & $\begin{array}{l}f_{y}^{B}(k, l)=4 l^{25} k^{.25} \\
U(x)=3800 x-400 x^{2}\end{array}$ & 5 & 4 & 5 \\
\hline 7 & B & $\begin{array}{l}\text { Producer of } \mathrm{Z} \\
\text { Consumer of } \mathrm{X} \text { and } \mathrm{Y}\end{array}$ & $\begin{aligned} & f_{Z}^{B}(k, l)=2 l^{25} k^{25} \\
& U(x, y)=3800 x-400 x^{2}+3900 y \\
&-400 y^{2}\end{aligned}$ & 5 & 4 & 4 \\
\hline 8 & B & $\begin{array}{l}\text { Supplier of L and } \mathrm{K} \\
\text { Consumer of } \mathrm{Z}\end{array}$ & $\begin{array}{l}C(l, k)=48 l+15 l^{2}+4.091 k+ \\
7.5 k^{2} \\
U(z)=5600 z-400 z^{2}\end{array}$ & 5 & 4 & 5 \\
\hline 9 & $\mathrm{C}$ & $\begin{array}{l}\text { Producer of } \mathrm{X} \\
\text { Consumer of } \mathrm{Y} \text { and } \mathrm{Z}\end{array}$ & $\begin{array}{l}f_{x}^{C}(k, l)=2 l^{25} k^{25} \\
U(y, z)=13500 y-1000 y^{2}+ \\
16000 z-1000 z^{2}\end{array}$ & 5 & 4 & 5 \\
\hline 10 & $\mathrm{C}$ & $\begin{array}{l}\text { Producer of } \mathrm{Y} \\
\text { Consumer of } \mathrm{X} \text { and } \mathrm{Z}\end{array}$ & $\begin{array}{l}f_{y}^{C}(k, l)=2 l^{25} k^{25} \\
U(x, z)=12000 x-1000 x^{2}+ \\
16000 z-1000 \mathrm{z}^{2}\end{array}$ & 5 & 3 & 5 \\
\hline 11 & $\mathrm{C}$ & Producer of Z & $f_{z}^{C}(k, l)=4 l^{.25} k^{.25}$ & 5 & 2 & 4 \\
\hline 12 & $\mathrm{C}$ & $\begin{array}{l}\text { Supplier of } \mathrm{L} \text { and } \mathrm{K} \\
\text { Consumer of } \mathrm{X} \text { and } \mathrm{Y}\end{array}$ & $\begin{array}{l}C(l, k)=300 l+50 l^{2}+220 k+ \\
20 k^{2} \\
U(x, y)=12000 x-1000 x^{2}+ \\
13500 z-1000 \mathrm{z}^{2}\end{array}$ & 5 & 3 & 5 \\
\hline
\end{tabular}


Table 2: Values of Parameters in Individual Demand, Production, and Supply Functions

\begin{tabular}{|c|c|c|c|}
\hline \multicolumn{4}{|c|}{ Demand $\left(a_{m}{ }^{J}, b_{m J}\right)$} \\
\hline & Country A & Country B & Country C \\
\hline Good $x$ & $3.5,0.005$ & $4.75,0.00125$ & $6,0.0005$ \\
\hline Good y & $8.25,0.005$ & $4.875,0.00125$ & $6.25,0.0005$ \\
\hline Good z & $9.5,0.005$ & $7,0.00125$ & $8,0.0005$ \\
\hline \multicolumn{4}{|c|}{ Supply $\left(c_{m}{ }^{J}, e_{m J}\right)$} \\
\hline & Country A & Country B & Country C \\
\hline Factor $l$ & $0.25,6.5$ & $1 / 30,1.6$ & $0.01,3$ \\
\hline Factor $k$ & $0.1,1$ & $1 / 15,11 / 3$ & $1 / 40,5.5$ \\
\hline \multicolumn{4}{|c|}{ Production $\left(H_{m}{ }^{J}\right)$} \\
\hline & Country A & Country B & Country C \\
\hline Good x & 4 & 2 & 2 \\
\hline Good y & 2 & 4 & 2 \\
\hline Good z & 2 & 2 & 4 \\
\hline
\end{tabular}


Table 3: Competitive Equilibrium and Autarky Prices, Wages, Trade Volumes, and Exchange Rates in the Experiments

\begin{tabular}{|c|c|c|c|c|c|c|}
\hline Variable & Compe & ve Mode & & Autark & Model & \\
\hline & Exp. 1 & Exp. 2 & Exp. 3 & Exp. 1 & Exp. 2 & Exp. 3 \\
\hline$p_{x}{ }^{A}$ & 539 & 567 & 497 & 205 & 206 & 184 \\
\hline$p_{y}{ }^{A}$ & 795 & 724 & 773 & 1036 & 1036 & 981 \\
\hline$p_{z}{ }^{A}$ & 1035 & 1008 & 1142 & 1193 & 1193 & 1275 \\
\hline$p_{x}^{B}$ & 1095 & 1249 & 1006 & 2034 & 2016 & 2111 \\
\hline$p_{y}{ }^{B}$ & 1614 & 1594 & 1564 & 855 & 850 & 851 \\
\hline$p_{z}^{B}$ & 2101 & 2219 & 2312 & 2994 & 2984 & 3847 \\
\hline$p_{x}{ }^{C}$ & 3329 & 4000 & 2567 & 7269 & 6587 & 7325 \\
\hline$p_{y}{ }^{C}$ & 4906 & 5106 & 3993 & 7569 & 8181 & 7629 \\
\hline$p_{z}{ }^{C}$ & 6385 & 7108 & 5902 & 4405 & 6187 & 5477 \\
\hline$w_{l}^{A}$ & 143 & 142 & 139 & 139 & 139 & 134 \\
\hline$w_{k}^{A}$ & 209 & 208 & 203 & 203 & 203 & 179 \\
\hline$w^{B}{ }_{l}$ & 537 & 544 & 514 & 531 & 527 & 557 \\
\hline$w_{k}^{B}$ & 391 & 396 & 375 & 387 & 384 & 406 \\
\hline$w^{C}{ }_{l}$ & 1942 & 2110 & 1811 & 1898 & 2024 & 1948 \\
\hline$w_{k}^{C}$ & 1235 & 1351 & 1162 & 1217 & 1295 & 1248 \\
\hline$I M P_{x}^{B}$ & 22 & 15 & 16 & 0 & 0 & 0 \\
\hline$I M P_{x}^{C}$ & 33 & 21 & 34 & 0 & 0 & 0 \\
\hline$I M P_{y}^{A}$ & 20 & 15 & 16 & 0 & 0 & 0 \\
\hline$I M P_{y}^{C}$ & 22 & 17 & 32 & 0 & 0 & 0 \\
\hline$I M P_{z}^{A}$ & 13 & 9 & 11 & 0 & 0 & 0 \\
\hline$I M P_{z}^{B}$ & 23 & 15 & 25 & 0 & 0 & 0 \\
\hline$r^{B}$ & 2.03 & 2.2 & 2.02 & - & - & - \\
\hline$r^{C}$ & 6.17 & 7.06 & 5.17 & - & - & - \\
\hline
\end{tabular}


Table 4: Estimates of Convergence Regression for Output Prices

\begin{tabular}{|l|l|l|l|l|l|}
\hline Variable & $\beta_{11}$ & $\beta_{12}$ & $\beta_{13}$ & $\beta_{2}$ & $R^{2}$ \\
\hline$p_{x}{ }^{A}$ & -26.8 & $-229.5^{*}$ & $-206.0^{*}$ & $-31.2^{*}$ & .65 \\
& $(36.4)$ & $(24.0)$ & $(85.6)$ & $(12.0)$ & \\
\hline$p_{y}{ }^{A}$ & $273.8^{*}$ & $557.8^{*}$ & -146.7 & $149.2^{*}$ & .76 \\
& $(121.4)$ & $(146.6)$ & $(148.8)$ & $(25.4)$ & \\
\hline$p_{z}{ }^{A}$ & -181.8 & 124.2 & -242.1 & $213.2^{*}$ & .62 \\
& $(133.6)$ & $(111.1)$ & $(136.8)$ & $(27.6)$ & \\
\hline$p_{x}{ }^{B}$ & $1915.6^{*}$ & $1307.6^{*}$ & 557.3 & $734.3^{*}$ & .86 \\
& $(495.8)$ & $(338.0)$ & $(417.9)$ & $(79.6)$ & \\
\hline$p_{y}{ }^{B}$ & 72.4 & -155.2 & -114.7 & 45.8 & .11 \\
& $(76.8)$ & $(165.9)$ & $(132.1)$ & $(24.7)$ & \\
\hline$p_{z}{ }^{B}$ & $2008.8^{*}$ & -153.9 & 280.1 & $1263.1^{*}$ & .91 \\
& $(714.5)$ & $(121.0)$ & $(182.2)$ & $(87.5)$ & \\
\hline$p_{x}{ }^{C}$ & $5966.6^{*}$ & 1434.8 & $2543.1^{*}$ & $2241.1^{*}$ & .89 \\
& $(1144.0)$ & $(914.6)$ & $(657.5)$ & $(171.8)$ & \\
\hline$p_{y}{ }^{C}$ & -1196.2 & $1687.2^{*}$ & 1566.4 & $2087.0^{*}$ & .76 \\
& $(1639.5)$ & $(771.7)$ & $(1422.4)$ & $(228.6)$ & \\
\hline$p_{z}{ }^{C}$ & $-6210.1^{*}$ & -2155.8 & 2696.2 & $1055.2^{*}$ & .49 \\
& $(2732.9)$ & $(1191.2)$ & $(1351.3)$ & $(328.7)$ & \\
\hline
\end{tabular}

*: significantly different from zero at the $\mathrm{p}<.05$ level. 
Table 5: Estimates of Convergence Regression for Input Prices and Exchange Rates

\begin{tabular}{|l|l|l|l|l|l|}
\hline Variable & $\beta_{11}$ & $\beta_{12}$ & $\beta_{13}$ & $\beta_{2}$ & $R^{2}$ \\
\hline$w_{l}{ }^{A}$ & $440.2^{*}$ & $163.8^{*}$ & 13.9 & 54.0 & .74 \\
& $(151.0)$ & $(42.8)$ & $(37.1)$ & $(14.8)$ & \\
\hline$w_{k}{ }^{A}$ & $564.5^{*}$ & 35.9 & -33.5 & 15.8 & .70 \\
& $(161.1)$ & $(44.4)$ & $(38.6)$ & $(15.7)$ & \\
\hline$w_{l}^{B}$ & $707.1^{*}$ & $-167.8^{*}$ & -82.2 & $104.1^{*}$ & .63 \\
& $(257.1)$ & $(45.3)$ & $(78.0)$ & $(28.5)$ & \\
\hline$w_{k}^{B}$ & $657.2^{*}$ & -106.8 & -41.7 & $171.9^{*}$ & .74 \\
& $(227.9)$ & $(63.8)$ & $(81.0)$ & $(26.7)$ & \\
\hline$w_{l}^{C}$ & $-264.4^{*}$ & -477.3 & -116.3 & 89.4 & .14 \\
& $(127.2)$ & $(330.9)$ & $(367.0)$ & $(58.1)$ & \\
\hline$w_{k}^{C}$ & $-210.4^{*}$ & 51.8 & 69.8 & $210.0^{*}$ & .59 \\
& $(90.9)$ & $(122.7)$ & $(139.6)$ & $(29.8)$ & \\
\hline$r^{B}$ & 1.33 & $-1.71^{*}$ & $2.53^{*}$ & $.62^{*}$ & .50 \\
& $(.90)$ & $(.52)$ & $(.51)$ & $(.14)$ & \\
\hline$r^{C}$ & $-15.06^{*}$ & $-7.84^{*}$ & $6.36^{*}$ & $1.63^{*}$ & .72 \\
& $(2.49)$ & $(1.45)$ & $(1.42)$ & $(.38)$ & \\
\hline
\end{tabular}

*: significantly different from zero at the $\mathrm{p}<.05$ level. 
Table 6: Estimates of Convergence Regression for Imports and Production by Country

\begin{tabular}{|c|c|c|c|c|c|}
\hline Variable & $\beta_{11}$ & $\beta_{12}$ & $\beta_{13}$ & $\beta_{2}$ & $R^{2}$ \\
\hline$I M P_{x}^{B}$ & $\begin{array}{l}-27.4^{*} \\
(5.6)\end{array}$ & $\begin{array}{l}-15.7^{*} \\
(2.3)\end{array}$ & $\begin{array}{l}-6.9 \\
(4.6)\end{array}$ & $\begin{array}{l}-8.1^{*} \\
(0.9)\end{array}$ & .89 \\
\hline$I M P_{x}{ }^{C}$ & $\begin{array}{l}-31.9 * \\
(2.5)\end{array}$ & $\begin{array}{l}-26.7^{*} \\
(4.3)\end{array}$ & $\begin{array}{l}-20.7 * \\
(2.3)\end{array}$ & $\begin{array}{l}-15.2^{*} \\
(1.0)\end{array}$ & .93 \\
\hline$I M P_{y}^{A}$ & $\begin{array}{l}-29.4^{*} \\
(7.1)\end{array}$ & $\begin{array}{l}-17.8^{*} \\
(4.5)\end{array}$ & $\begin{array}{l}9.8 \\
(7.3)\end{array}$ & $\begin{array}{l}-5.2^{*} \\
(1.2)\end{array}$ & .73 \\
\hline$I M P_{y}{ }^{C}$ & $\begin{array}{l}-23.4^{*} \\
(3.5)\end{array}$ & $\begin{array}{l}-12.9^{*} \\
(2.7)\end{array}$ & $\begin{array}{l}-41.2^{*} \\
(7.1)\end{array}$ & $\begin{array}{l}-13.6^{*} \\
(1.1)\end{array}$ & .92 \\
\hline$I M P_{z}^{A}$ & $\begin{array}{l}-11.6^{*} \\
(2.1)\end{array}$ & $\begin{array}{l}-16.6^{*} \\
(5.7)\end{array}$ & $\begin{array}{l}-3.1 \\
(3.9)\end{array}$ & $\begin{array}{l}-1.9 \\
(1.2)\end{array}$ & .44 \\
\hline$I M P_{z}^{B}$ & $\begin{array}{l}-25.4^{*} \\
(4.1)\end{array}$ & $\begin{array}{l}-13.1^{*} \\
(1.8)\end{array}$ & $\begin{array}{l}-30.9 * \\
(4.6)\end{array}$ & $\begin{array}{l}-13.6^{*} \\
(0.9)\end{array}$ & .95 \\
\hline $\operatorname{Prod}_{x}^{A}$ & $\begin{array}{l}-49.4^{*} \\
(5.1)\end{array}$ & $\begin{array}{l}-41.6^{*} \\
(6.6)\end{array}$ & $\begin{array}{l}-18.7 * \\
(7.1)\end{array}$ & $\begin{array}{l}-22.1^{*} \\
(1.5)\end{array}$ & .93 \\
\hline $\operatorname{Prod}_{y}{ }^{A}$ & $\begin{array}{l}-12.2^{*} \\
(2.9)\end{array}$ & $\begin{array}{l}2.6 \\
(3.1)\end{array}$ & $\begin{array}{l}16.7^{*} \\
(1.6)\end{array}$ & $\begin{array}{l}2.3^{*} \\
(0.8)\end{array}$ & .59 \\
\hline $\operatorname{Prod}_{z}^{A}$ & $\begin{array}{l}-34.2^{*} \\
(10.8)\end{array}$ & $\begin{array}{l}-6.8 \\
(4.6)\end{array}$ & $\begin{array}{l}12.8 \\
(8.1)\end{array}$ & $\begin{array}{l}4.9^{*} \\
(1.6)\end{array}$ & .54 \\
\hline $\operatorname{Prod}_{x}^{B}$ & $\begin{array}{l}-1.1 \\
(1.7)\end{array}$ & $\begin{array}{l}-13.1^{*} \\
(2.7)\end{array}$ & $\begin{array}{l}12.9 \\
(8.0)\end{array}$ & $\begin{array}{l}6.6^{*} \\
(1.0)\end{array}$ & .69 \\
\hline $\operatorname{Prod}_{y}{ }^{B}$ & $\begin{array}{l}-53.0^{*} \\
(5.6)\end{array}$ & $\begin{array}{l}-28.6^{*} \\
(2.5)\end{array}$ & $\begin{array}{l}-33.0 * \\
(3.0)\end{array}$ & $\begin{array}{l}-18.0 * \\
(1.0)\end{array}$ & .58 \\
\hline $\operatorname{Prod}_{z}^{B}$ & $\begin{array}{l}-15.9 * \\
(2.4)\end{array}$ & $\begin{array}{l}-6.2^{*} \\
(3.0)\end{array}$ & $\begin{array}{l}1.5 \\
(1.2)\end{array}$ & $\begin{array}{l}3.5 \\
(0.7)\end{array}$ & .53 \\
\hline $\operatorname{Prod}_{x}{ }^{C}$ & $\begin{array}{l}-11.7 * \\
(3.7)\end{array}$ & $\begin{array}{l}2.2 \\
(1.2)\end{array}$ & $\begin{array}{l}14.2 * \\
(3.8)\end{array}$ & $\begin{array}{l}13.6^{*} \\
(0.9)\end{array}$ & .90 \\
\hline $\operatorname{Prod}_{y}{ }^{C}$ & $\begin{array}{l}-13.5^{*} \\
(4.2)\end{array}$ & $\begin{array}{l}3.3^{*} \\
(1.3)\end{array}$ & $\begin{array}{l}6.5 \\
(3.8)\end{array}$ & $\begin{array}{l}9.9 * \\
(0.7)\end{array}$ & .84 \\
\hline $\operatorname{Prod}_{z}{ }^{C}$ & $\begin{array}{l}-59.2^{*} \\
(4.0)\end{array}$ & $\begin{array}{l}-29.9^{*} \\
(1.8)\end{array}$ & $\begin{array}{l}-53.2^{*} \\
(1.4)\end{array}$ & $\begin{array}{l}-17.1^{*} \\
(1.1)\end{array}$ & .74 \\
\hline
\end{tabular}

*: significantly different from zero at the $\mathrm{p}<.05$ level. 
Table 7: Estimates of Convergence Regression for Differences Between Observed and PPP Exchange Rates

\begin{tabular}{|l|l|l|l|l|l|}
\hline Variable & $\beta_{11}$ & $\beta_{12}$ & $\beta_{13}$ & $\beta_{2}$ & $R^{2}$ \\
\hline$r_{A}-r_{A}{ }^{P P P}$ & -.738 & $-1.045^{*}$ & $1.603^{*}$ & .240 & .40 \\
& $(.690)$ & $(.394)$ & $(.385)$ & $(.103)$ & \\
\hline$r_{B}-r_{B}{ }^{P P P}$ & $-6.730^{*}$ & $-5.381^{*}$ & 2.200 & .281 & .49 \\
& $(2.020)$ & $(1.175)$ & $(1.151)$ & $(.311)$ & \\
\hline
\end{tabular}

*: significantly different from zero at the $\mathrm{p}<.05$ level. 
Figure 1: The Structure of the Economies

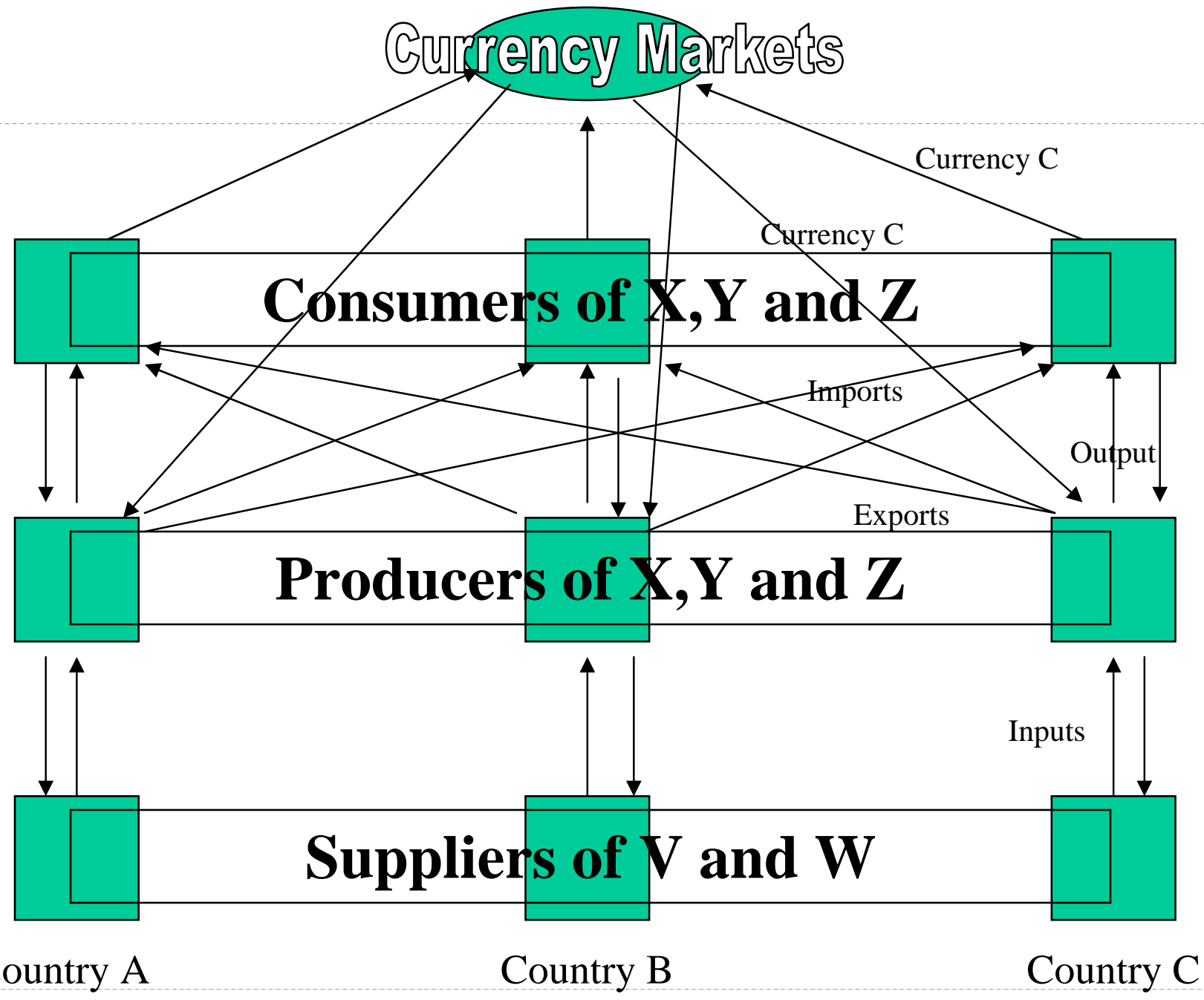


Figure 2: The Market Summary Screen

MARKET

SUMMARY
ID: 1 Period 12 Remaining:

(A)
Apr 16

10:21:58 $\underline{\text { RELOAD }}$

Order

Your Your Buy Sell Last My My

Market Units Currency Offer Offer Trade Offers Trades Graph History $\mathbb{C}$ Buy

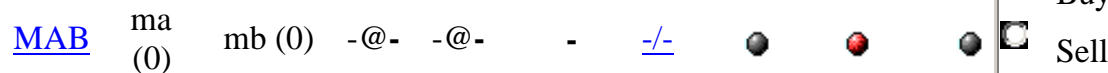

MAC ma mc (0) - @- -@-

$\underline{\mathrm{XA}} \times(0)$ ma (0) -@- -@- -

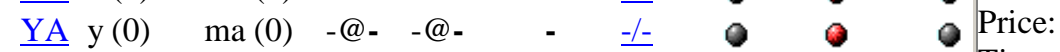

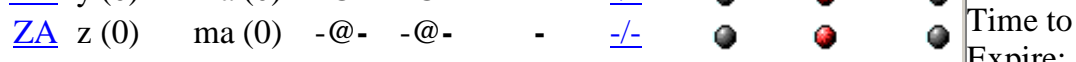

VA v (0) ma(0) -@- -@- $\quad-\quad \frac{-/}{-} 0$ Expire:

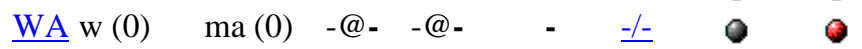

PrivateX1 x (0) ma(0) -@- -@- - -
0

(e.g. $1 \mathrm{~h} 6 \mathrm{~m} 5 \mathrm{~s} ;$ $0=$ never expire)

Clear

$\underline{\text { Home }} \frac{\underline{\text { Country }}}{\underline{\mathrm{A}}} \frac{\underline{\text { Country }}}{\underline{B}} \underline{\text { Country }} \underline{\underline{\text { Instructions }}} \underline{\underline{\text { and Help }}} \underline{\text { Inventory Production }} \underline{\underline{\text { Graph }}} \underline{\underline{\text { All }}} \underline{\text { Announcements }} \underline{\text { LOGOUT }}$ Markets 
Figure 3: Production Function Display

\section{Table of production of $\mathrm{X}$ from $\mathrm{V}$ and $\mathrm{W}$}

\begin{tabular}{|l||l|l|l|l|l|l|l|l|l||}
\hline \multicolumn{1}{||||}{ V } & \multicolumn{9}{|l||}{ Amount Produced } \\
\hline 8 & 0 & 7 & 8 & 9 & 10 & 10 & 11 & 11 & 12 \\
\hline 7 & 0 & 7 & 8 & 9 & 9 & 10 & 10 & 11 & 11 \\
\hline 6 & 0 & 6 & 7 & 8 & 9 & 9 & 10 & 10 & 11 \\
\hline 5 & 0 & 6 & 7 & 8 & 8 & 9 & 9 & 10 & 10 \\
\hline 4 & 0 & 6 & 7 & 7 & 8 & 8 & 9 & 9 & 10 \\
\hline 3 & 0 & 5 & 6 & 7 & 7 & 8 & 8 & 9 & 9 \\
\hline 2 & 0 & 5 & 6 & 6 & 7 & 7 & 7 & 8 & 8 \\
\hline 1 & 0 & 4 & 5 & 5 & 6 & 6 & 6 & 7 & 7 \\
\hline 0 & 0 & 0 & 0 & 0 & 0 & 0 & 0 & 0 & 0 \\
\hline \hline & 0 & 1 & 2 & 3 & 4 & 5 & 6 & 7 & 8 \\
\hline
\end{tabular}


Figure 4: Output Prices in the Three Counties, Experiment 3

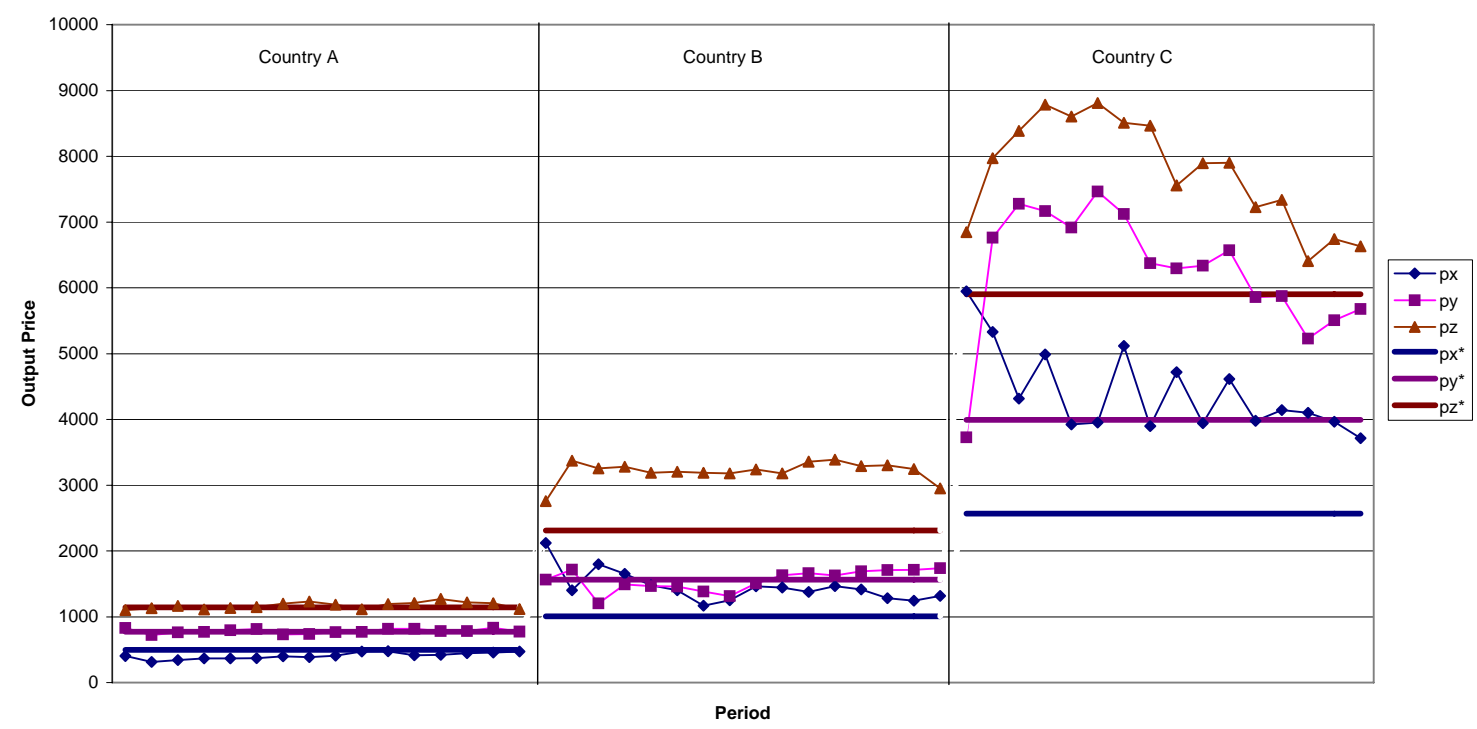


Figure 5: Input Prices in the Three Countries, Experiment 3

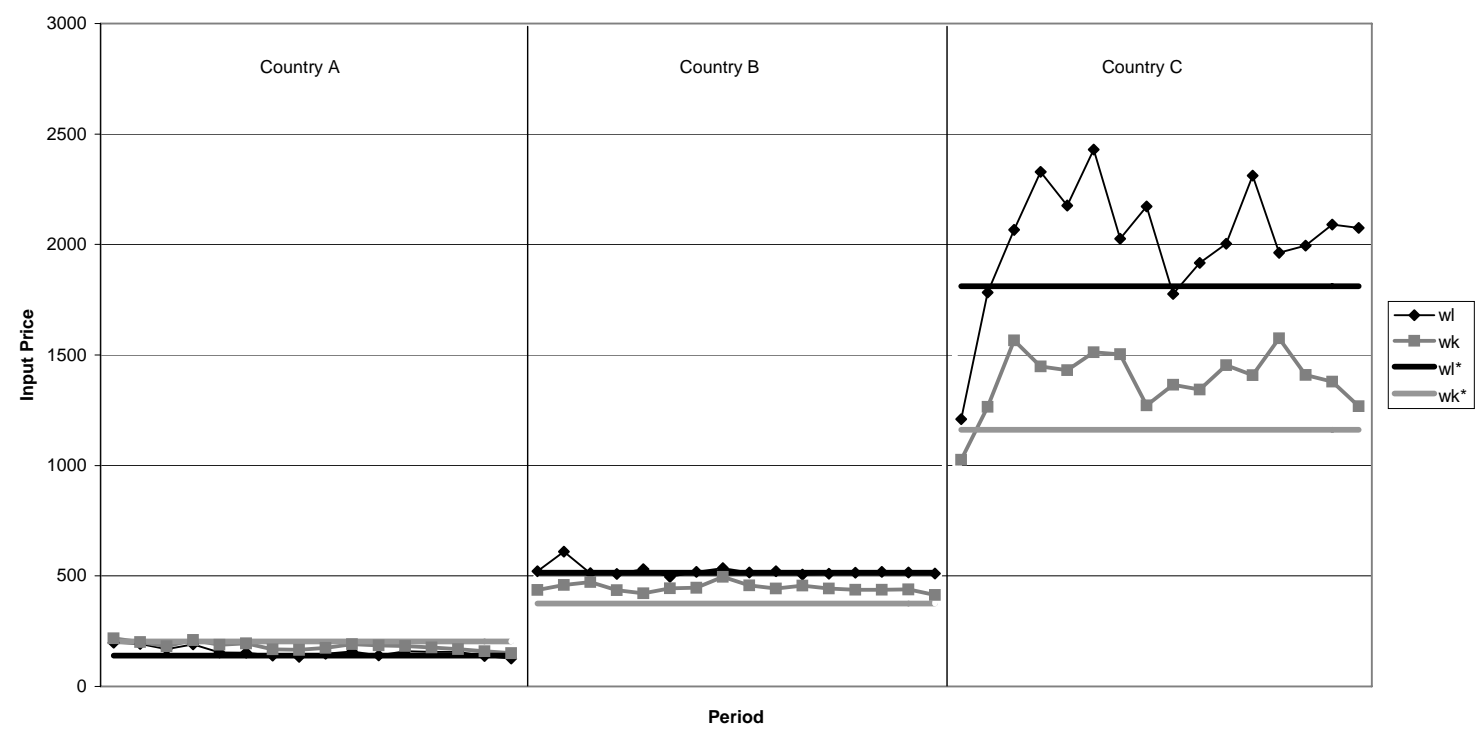


Figure 6: Observed, Equilibrium and PPP Exchange Rates, Experiment 3

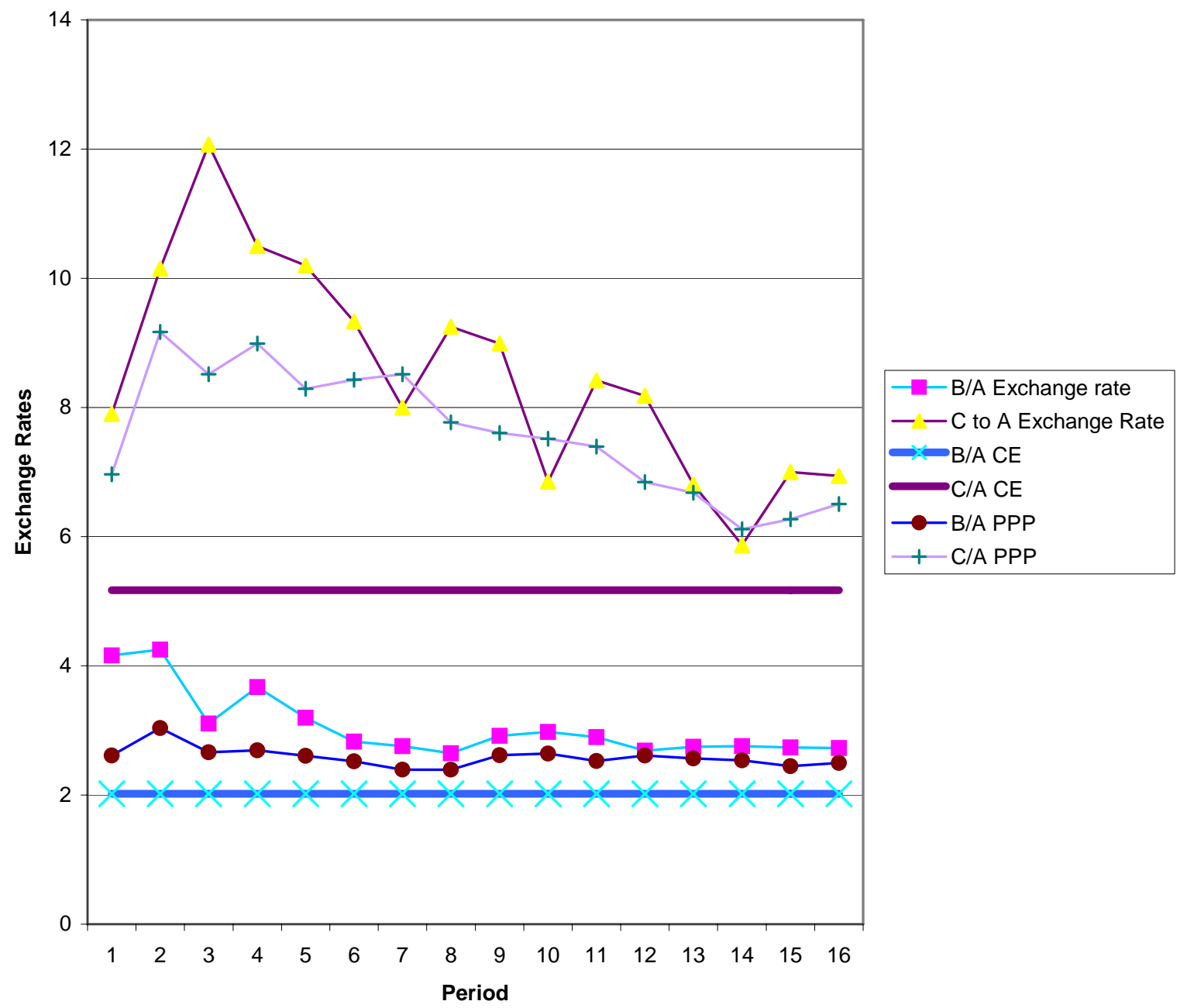


Figure 7: Time series of Wages for $L$ in country A, Experiment 1

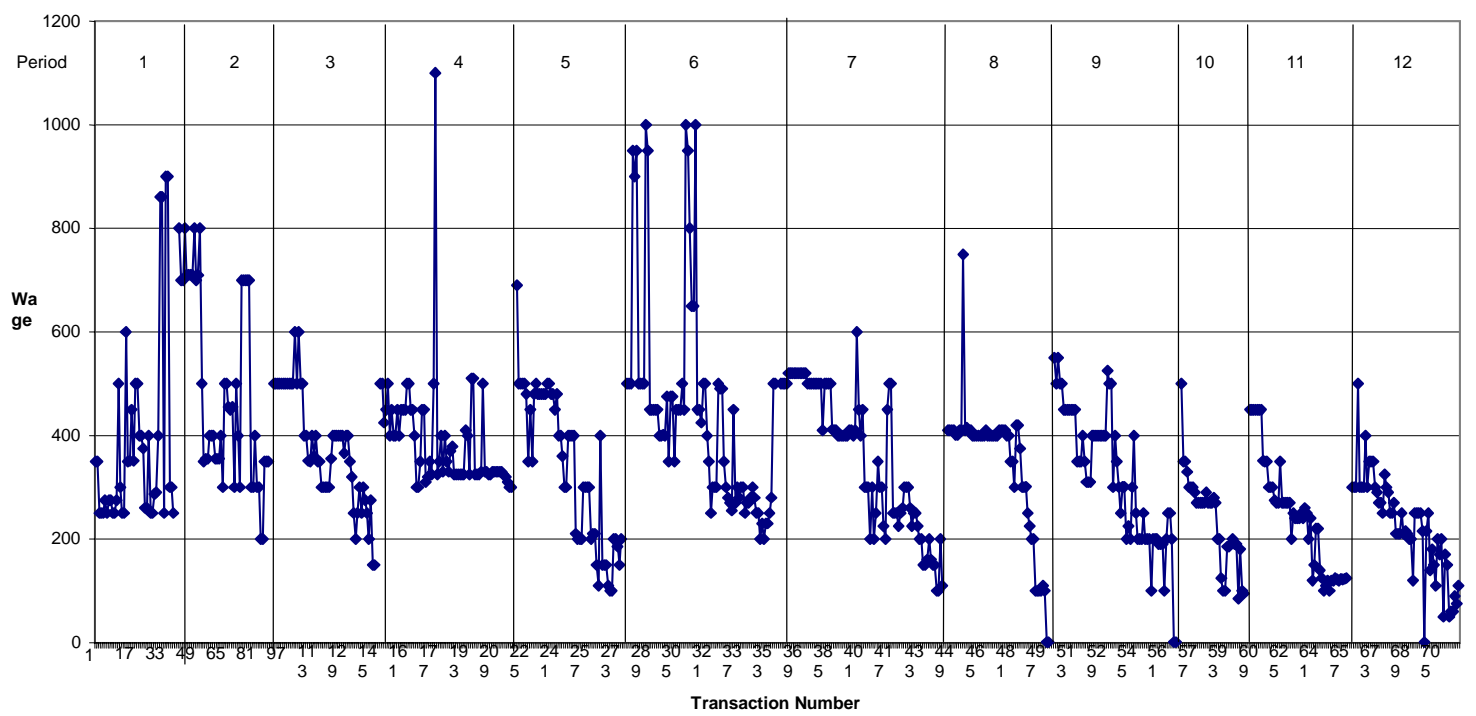

36 


\section{Appendix}

The following pages contain the specific instructions used for this experiment. Additional instructions on the use of the Marketscape trading system itself are available from the authors.

\section{DETAILED INSTRUCTIONS}

\section{Overview}

The experiment will be divided into periods. All markets will be open for an announced time after which all markets will close. Each period starts fresh with new opportunities. Inventories, cash, commitments, etc. do not carry over from period to period (unless you are told otherwise). Each period is new and possibly unrelated to periods of the past. This will be explained in more detail later.

In the market there are three different goods called $\mathrm{X}, \mathrm{Y}$, and $\mathrm{Z}$ and there are two resources called $\mathrm{V}$ and $\mathrm{W}$. There are three different locations, which you can think of as different countries. The countries are called A, B, and C. Each participant has a home at one of these countries. In each of the three countries there are markets for all goods and all resources, five markets in total for $\mathrm{V}, \mathrm{W}, \mathrm{X}, \mathrm{Y}$, and $\mathrm{Z}$. There is a currency in each country. All purchases and sales in country A must take place in terms of currency A. Likewise, all purchases and sales in countries B and C, must take place in terms of currencies B and C, respectively.

There are three different roles for participants: "consumers", "producers" and "suppliers".

Participants can have multiple roles. Each participant also has a home country, either A, B, or C. You can convert the currency of your home country to U.S. dollars, which are yours to keep, at the end of the experiment, at a rate shown on your home pages. Foreign currency has value to you only in that it allows you to make purchases in other countries.

\section{THREE TYPES OF ROLES}

CONSUMERS have access to one or more private markets in which the experimenter has placed orders. These markets are called PrivateX, PrivateY and PrivateZ. Consumers can make money by purchasing $\mathrm{X}, \mathrm{Y}$, and $\mathrm{Z}$ in public markets and then reselling in their private markets. They can buy $X, Y$ and $Z$ in any of the three countries, e.g. the market for $\mathrm{X}$ in country $\mathrm{B}$ is called $\mathrm{XB}$. After buying $\mathrm{X}, \mathrm{Y}$, and $\mathrm{Z}$, they can consume it by selling it to the experimenter in their private markets. If the expenditures for $\mathrm{X}, \mathrm{Y}$, and $\mathrm{Z}$ in any given period of the experiment are less than the income from the sale in private markets, the consumer has made a profit which is his or hers to keep. This "profit" is measured in terms of home currency, which can be converted to U.S. dollars are the rate shown on the home page. 
Briefly, $\mathrm{X}, \mathrm{Y}$ and $\mathrm{Z}$ and money have value to consumers. $\mathrm{V}$ and $\mathrm{W}$ have no value to consumers.

$\mathrm{X}, \mathrm{Y}$, and $\mathrm{Z}$ have value only if they are consumed. $\mathrm{X}$ has the same value to a consumer no matter in which country it was produced. The same is true for $\mathrm{Y}$ and $\mathrm{Z}$.

PRODUCERS have the ability to use $\mathrm{V}$ and $\mathrm{W}$ to make one type of output. It will be either X, Y, or Z. They can use home currency to buy V and W from suppliers in their home country. The $\mathrm{V}$ and $\mathrm{W}$ can be used by the producer to produce output, which can then be sold for money to anyone who wishes to buy it. Producers can study the possibilities for production by using the Production Page link found at the bottom of the market page. The form found there takes $\mathrm{V}$ and $\mathrm{W}$ as inputs and transforms them into $\mathrm{X}$, $\mathrm{Y}$, or $\mathrm{Z}$, depending upon the particular producer.

The schedule that dictates the terms of the transformation can be found by clicking on the Production Table link, on the Production page. The Production Table indicates the amount of output that results from using various levels of $\mathrm{V}$ and $\mathrm{W}$.

The relationship between inputs and outputs depends on past production until refreshed at the start of a new period. The lighted square indicates the relevant past production. If the lighted square is at $(0,0)$ then the point $(0,0)$ is used to measure the sensitivity of output levels to use of V and $\mathrm{W}$ inputs. If you find the lighted square somewhere other than $(0,0)$ in the table it means that you have used inputs up to that point and the sensitivity of production to further $\mathrm{V}$ and $\mathrm{W}$ inputs will be measured from the lighted square on. At the end of the period, production will be refreshed and you will start from the $(0,0)$ point again.

Briefly, V, W, X, Y, and Z have no value to producers. However, producers can use V and $\mathrm{W}$ to produce $\mathrm{X}, \mathrm{Y}$, or $\mathrm{Z}$. They can sell output to consumers who would like to consume them. The money received from selling $\mathrm{X}, \mathrm{Y}$, or $\mathrm{Z}$, has value as it is converted to dollars at the end of the experiment.

If the total proceeds from the sale of output in any given period of the experiment is greater than the total cost of purchasing $\mathrm{V}$ and $\mathrm{W}$ in the period, the producer has made a profit which is his or hers to keep. That is, if the price of output times the units produced from the application of $\mathrm{V}$ and $\mathrm{W}$ is higher than the cost of the units of $\mathrm{V}$ and $\mathrm{W}$ used to produce it, then the producer has made a profit on that effort.

SUPPLIERS have a private market in which they can purchase $\mathrm{V}$ and $\mathrm{W}$. They can sell this $\mathrm{V}$ and $\mathrm{W}$ to anybody in their own country who wishes to purchase it. $\mathrm{V}$ and $\mathrm{W}$ have no value as consumption to suppliers. However, the money received from the sale of $\mathrm{V}$ and $\mathrm{W}$ does have value as it is converted to dollars at the end of the experiment.

Thus, if the proceeds from the sale of $\mathrm{V}$ and $\mathrm{W}$ in any given period of the experiment is greater than the cost of purchasing $\mathrm{V}$ and $\mathrm{W}$ in the private markets in the period, the supplier has made a profit which is his or hers to keep. If a supplier sells a unit of $\mathrm{V}$ or $\mathrm{W}$ 
for a higher price than he/she purchased it for in the private market, the supplier has made a profit on that unit.

\section{TRADING PROFITS AND IMPORTING}

TRADING: A potential source of profits is from buying and reselling the five types of goods. Buying reduces your cash by the amount of the purchase. Selling increases your cash by the amount of the sale. Thus you can either gain or lose money on the purchase and resale of units.

It is also possible to make profits from buying and reselling foreign currency. If you buy foreign currency and it increases in value relative to your home currency, and you convert it back to you home currency, you can make money. However, if you buy foreign currency and it declines in value you can lose money.

IMPORTING: You have many markets available. Shopping and trading among them might be a source of profits. You have the capacity to buy anything (except V and W) in a foreign country and sell it at home. That is, you can import anything (except V and W) from anywhere and sell it at home. You cannot sell anything (except currency) in a foreign market. Thus if prices in a foreign country are low enough you can use home currency to buy the foreign currency in either the home market or the foreign currency market. You can use the foreign currency to buy foreign goods which you can then sell in the home market or in a private market. Briefly put, after buying foreign currency you can imagine yourself in a foreign country with an inventory of that country's currency. Should you find it advantageous, you could buy X, Y, or Z there instead of buying it in your own country.

\section{TIMING OF THE EXPERIMENT}

There will be a sequence of market periods. The values in your private markets last for a period and then will disappear. Similarly, all units will disappear at the end of a period and home currency will be transformed to U.S. currency. When a new period opens, you will have new orders in your private markets and a new loan of your home currency.

\section{$<$ INSERT SCHEDULE OF EXPERIMENT HERE >}

\section{ENDING}

At the end of each period your holdings of home currency will be converted to dollars at the rate shown on your home market page. All inventories of foreign currencies and units will be gone (automatically removed from the system). So, near the end of a period you need to consider clearing (selling) all inventories because what you are holding other than home currency will be worthless. 


\section{HOW YOU MAKE MONEY}

EXAMPLE 1: Suppose you are a supplier in country A. The experimenter has placed a sell order in your private $\mathrm{W}$ market for one unit of $\mathrm{W}$ for 50 units of currency A. You buy the unit for 50 units of currency A, your home currency. Your inventory of currency A decreases by 50 and you have the unit of W. Suppose you are able to sell the unit of W for 90 units of currency A. From this sequence of transactions you have made 40 units of currency A, which are your to keep. If the conversion rate of currency A to US dollars is 200 currency A per dollar, you have made 20 cents on the sequence of transactions.

EXAMPLE 2: Suppose you are a producer of $Y$ in country B. You see the prices of V and $\mathrm{W}$ in your country at 300 per unit of $\mathrm{V}$ and 500 per unit of W. You see the price of $\mathrm{Y}$ in your country equals 1000 . You have 2000 units of currency B cash on hand. Suppose that using your production table, you are able use a unit of $\mathrm{V}$ and a unit of $\mathrm{W}$ to produce a unit of Y. You buy a unit of V at 300 and a unit of W at 500 for a total outlay of 800 . Then you use the $\mathrm{V}$ and $\mathrm{W}$ to produce $\mathrm{X}$, which you are able to sell for 1000 . You have made a profit of 200 currency B. That is, you have the 2000 units of currency B you started out with plus 200 more profit. You are now in a position to invest again in $\mathrm{V}$ and $\mathrm{W}$ to make more profit. If the conversion rate of currency B to US dollars is 100 currency B to 1 dollar, you have made 2 dollars on the sequence of transactions just described.

EXAMPLE 3: Suppose you are a consumer in country C. The experimenter has placed a buy order in your private $\mathrm{Z}$ market for one unit of $\mathrm{Z}$ at a price of 500 in terms of currency C. Suppose you go to the home $\mathrm{Z}$ market and you buy the unit of $\mathrm{Z}$ for 350 units of currency $C$. Then, you sell the unit to the experimenter for stated price of 500 in the private $\mathrm{Z}$ market. From this sequence of transactions you have made 150 units of currency $\mathrm{C}$, which are yours to keep. If the conversion rate of currency $\mathrm{C}$ to US dollars is 50 currency $\mathrm{C}$ per dollar, you have made 3 dollars on the sequence of transactions.

MISSED OPPORTUNITIES: Inventories of X, Y, and Z might be held as inventory only if some particular advantage can be determined. Remember that the opportunities afforded by private markets disappear when the private market orders expire at the end of the period. At that time the inventories are worth nothing. Thus, in most cases it is to your advantage to take advantage of the private market order while the order exists and acquire new units to take advantage of new orders in the private markets. 


\title{
Specialized Terms
}

\author{
ma Currency for country A (m stands for money) \\ $\mathrm{mb} \quad$ Currency for country B \\ mc Currency for country C \\ XA Public market for good $\mathrm{X}$ in country A \\ $\mathrm{XB} \quad$ Public market for good $\mathrm{X}$ in country $\mathrm{B}$ \\ YA Public market for good $\mathrm{Y}$ in country A \\ PrivateY235 Id 235's private Y market. Note, only I.D. 235 sees this, and all your \\ private markets will be in your home country. \\ MAB The currency market in country A where people buy or sell units of \\ currency A (ma) with prices quoted in terms of currency B (mb). So, if \\ the price is 2 and you put in a sell order to sell 1 unit of currency A (ma) \\ at a price of 2, you will get 2 units of currency B (mb). \\ MBA The currency market in country B where people buy or sell units of \\ currency B (mb) with prices quoted in terms of currency A (ma).
}

